\title{
Study of hydraulic fracturing processes in shale formations with complex geological settings
}

\author{
Bruno Figueiredo ${ }^{1}$, Chin-Fu Tsang ${ }^{1,2}$, Jonny Rutqvist ${ }^{2}$ and Auli Niemi ${ }^{1}$
}

\begin{abstract}
Hydraulic fracturing has been applied to extract gas from shale-gas reservoirs. Complicated geological settings, such as spatial variability of the rock mass properties, local heterogeneities, complex in situ stress field, and pre-existing bedding planes and faults, could make hydraulic fracturing a challenging task. In order to effectively and economically recover gas from such reservoirs, it is crucial to explore how hydraulic fracturing performs in such complex geological settings. For this purpose, numerical modelling plays an important role because such conditions cannot be reproduced by laboratory experiments. This paper focuses on the analysis of the influence of confining formations and preexisting bedding planes and faults on the hydraulically-induced propagation of a vertical fracture, which will be called injection fracture, in a shale-gas reservoir. An elastic-brittle model based on material property degradation was implemented in a $2 \mathrm{D}$ finite-difference scheme and used for rock elements subjected to tension and shear failure. A base case is considered, in which the ratio $S R$ between the magnitudes of the horizontal and vertical stresses, the permeability $k_{c}$ of the confining formations, the elastic modulus $E_{p}$ and initial permeability $k_{p}$ of the bedding plane and the initial fault permeability $k_{F}$ are fixed at reasonable values. In addition, the influence of multiple bedding planes, is investigated. Changes in pore pressure and permeability due to high pressure injection lasting 2 hours were analysed. Results show that in our case during the injection period the fracture reaches the confining formations and if the permeability of those layers is significantly larger than that of the shale, the pore pressure at the extended fracture tip decreases and fracture propagation becomes slower. After shut-in, the pore pressure decreases more and the fracture does not propagate any more. For bedding planes oriented perpendicular to the maximum principal stress direction and with the same elastic properties as the shale formation, results were found not to be influenced by their presence. In such a scenario, the impact of multiple bedding planes on fracture propagation is negligible. On the other hand, a bedding plane softer than the surrounding shale formation leads to a fracture propagation asymmetrical vertically with respect to the centre of the injection fracture with a more limited upward fracture propagation. A pre-existing fault leads to a decrease in fracture propagation because of fault reactivation with shear failure. This results in a smaller increase in injection fracture permeability and a slight higher injection pressure than that observed without the fault. Overall, results of a sensitivity analysis show that fracture propagation is influenced by the stress ratio $S R$, the permeability $k_{c}$ of the confining formations and the initial permeability $k_{p}$ of the bedding plane more than the other major parameters.
\end{abstract}

Keywords: shale-gas, hydraulic fracturing stimulation, fracture propagation, elastic-brittle model, bedding plane, fault reactivation 


\section{INTRODUCTION}

The rapid increase in shale-gas energy production, particularly in North America, has been made possible through techniques such as extended-reach horizontal drilling and multi stage hydraulicfracture stimulation. The cost for a hydraulic fractured well can amount to millions of dollars and the benefits from better understanding and controlling of this technology are obvious.

The complexity in the shale-gas formation, such as anisotropic in situ stress state, the spatial variability of rock mass properties (e.g., permeability, porosity and elastic modulus, density) ([1], [2]), the existence of multi-layers ([3]), the existence of layer interfaces ([4], [5]) the temperature ([6]), the competition between hydraulic fractures, and their recession and closure ([7]), may significantly influence the propagation of fractures in shale-gas reservoirs. Undesirable hydraulic fracturing results will not only cause economic loss but may also increase the risk of environment pollution, such as water contamination caused by the hydraulically induced fractures penetrating into groundwater layer. Hydraulic fracturing has raised concerns related to a range of environmental problems ([8], [9]). Thus, it is important to be able to predict the initiation and propagation of hydraulic fractures ([10]) in a formation with complex geological structures and stress conditions.

The reactivation of pre-existing faults and associated induced earthquakes have received increased attention of shale-gas stake holders and the general public. Several numerical studies have been made to evaluate the consequences of fault reactivation and induced seismicity during shale-gas hydraulic fracturing operations. In [11], a 2D numerical study is presented showing that hydraulic fracturing of a deep shale-gas reservoir leads to a limited fault rupture and possible micro-seismicity. However in 2D plane-strain simulations, it is difficult to estimate a representative injection rate, and some assumptions have to be made about the shape of the rupture area (e.g. circular with diameter equal to 2D rupture length), which affects the calculated seismic magnitude. Thus, [12] present a full 3D model simulation of fault activation associated with shale-gas fracturing. In this modelling, the injection rate representing one fracturing stage was a direct model input, and seismic magnitude was evaluated directly from the calculated rupture area and mean slip without the model uncertainties inherent in a 2D simplification.

One concern, which is the focus of the present study, is how geological structures such as confining formations, pre-existing bedding planes and faults influence fracture propagation during hydraulic fracturing operations. A model based on degradation of material properties is implemented in FLAC3D ([13]) to simulate fracture propagation in a continuous medium ([14]). The main objectives of the paper are (1) to check the effectiveness of using a continuum based model to simulate the fracture propagation (2) to study how fracture propagation is influenced by complex geological settings (e.g. confining formations, a pre-existing bedding plane and fault) and (3) to evaluate changes in pore pressure and permeability caused by the interaction between the propagating fracture and pre-existing geological structures. A sensitivity analysis is made to study the influence of the ratio $S R$ between the magnitude of horizontal and vertical boundary stresses, the permeability $k_{c}$ of confining formations, the elastic modulus $E_{p}$ and initial permeability $k_{p}$ of bedding plane, the initial permeability $k_{F}$ of the fault, as well as the effect of multiple bedding planes. The paper is completed with some concluding remarks. 


\section{PROBLEM DEFINITION}

Here the propagation of a vertical fracture through hydraulic fracturing is studied by water injection into a $2 \mathrm{~m}$ long vertical fracture, which shall be called the injection fracture. The injection fracture is defined having initial similar permeability and stiffness as the surrounding shale formation, but with null cohesion and tensile strength. Three scenarios were considered: in scenario 1 (SC1), a shale-gas reservoir with a thickness of $20 \mathrm{~m}$ located between two confining formations each with $15 \mathrm{~m}$ thickness, is considered; in scenario 2 (SC2), in addition to previous scenario, one pre-existing horizontal bedding plane located $1 \mathrm{~m}$ above the injection fracture upper tip, is considered; in scenario 3 (SC3), in addition to scenario 1 , a pre-existing fault with a dip angle of $60^{\circ}$, located near the injection fracture, is considered (Fig 1). In the last case SC3, the horizontal distance between the centre of the injection fracture and the fault is $1.0 \mathrm{~m}$, and the vertical distance between the tip of the injection fracture and the fault is $0.80 \mathrm{~m}$. These cases represent the basic scenarios on which various sensitivity analysis will be performed.
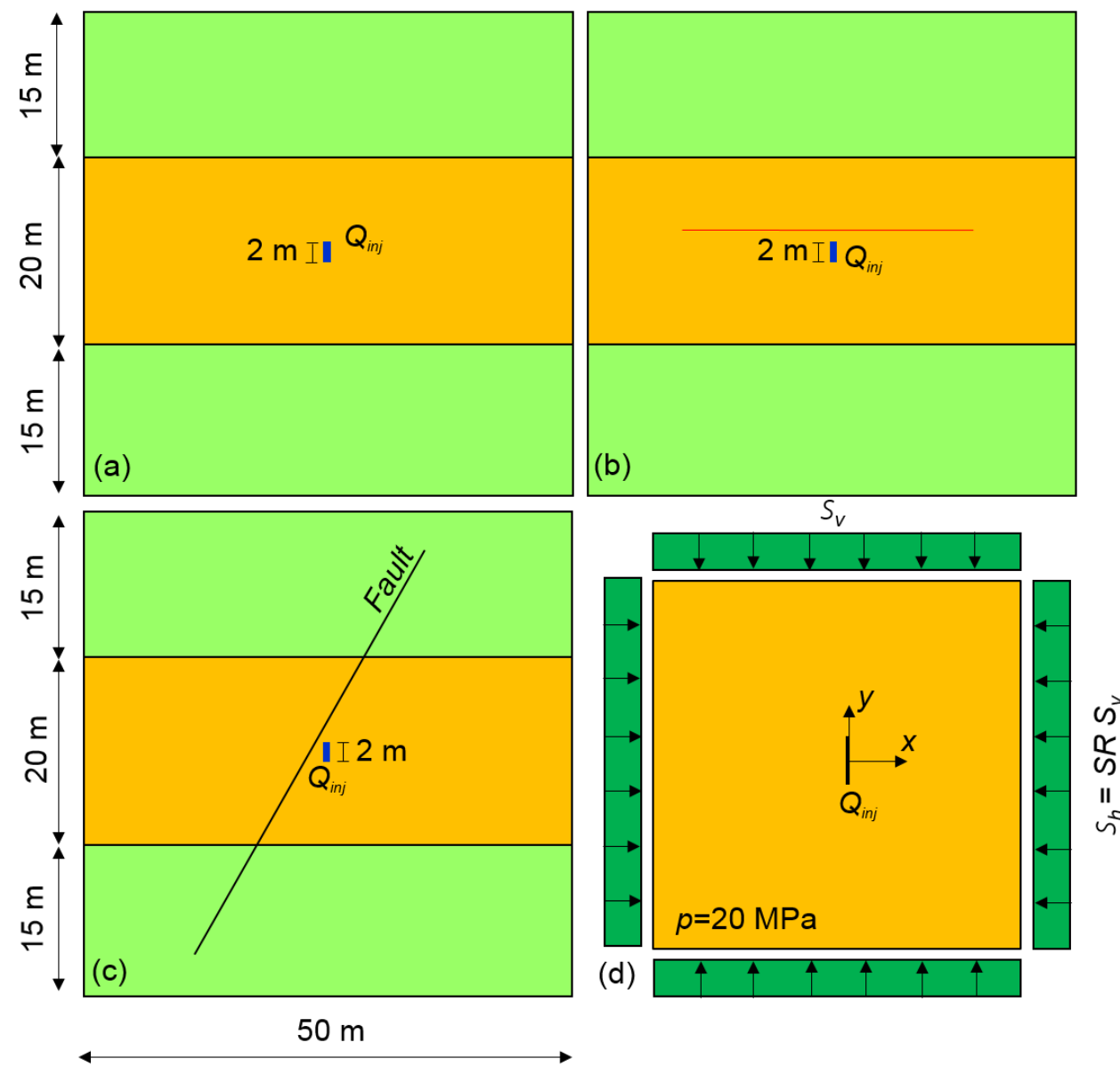

Fig. 1: Geometry of the scenarios (a) SC1 (b) SC2 (c) SC3 and (d) boundary loading and pore pressure conditions: $S_{v}$ and $S_{h}$ are the vertical and horizontal boundary stresses, respectively; $S R$ is the ratio between $S_{h}$ and $S_{v} ; p$ is the initial fluid pore pressure; $Q_{i n j}$ is the constant flow rate 
The origin of the $x$ and $y$-axis system is located in the centre of the studied regions. Let us now assume that the shale-gas reservoir is located at $2000 \mathrm{~m}$ depth. By assuming a vertical gradient of $0.027 \mathrm{MPa} / \mathrm{m}$, the magnitude of the vertical stress component $\left(S_{v}\right)$ at $2000 \mathrm{~m}$ depth below the surface is $54 \mathrm{MPa}$. The maximum boundary stress is vertical which is consistent with the injection fracture orientated according in the $y$-axis direction. A loading case was considered in which the ratio $S R$ between the horizontal $S_{h}$ and vertical $S_{v}$ boundary stresses is 0.7 (Fig. 1). Further, a sensitivity analysis is made to study the influence of $S R$ on the obtained results (see section 5.1). Because the vertical and horizontal dimensions of the model are only $50 \mathrm{~m}$, the vertical and horizontal gradients of all stress components were neglected. The stresses are applied normal to the boundaries which are free to move. No shear stresses are considered at the boundaries (Fig. 1). Results of our simulations showed that because the boundary conditions are imposed far enough, they do not influence the stresses around the injection fracture and its propagation in the intact rock. By assuming that the water table is located at the land surface and a fluid pore pressure vertical gradient of $0.01 \mathrm{MPa} / \mathrm{m}$, at 2000 $\mathrm{m}$ depth, the fluid pore pressure $p$ is $20 \mathrm{MPa}$. Over the 50 by $50 \mathrm{~m}$ model domain, the pore pressure gradients in the $x$ and $y$-axis directions were neglected. All the boundaries were considered closed to flow. Results of our simulations showed that the results are not influenced by the flow boundary conditions. We simulate a hydraulic fracturing stimulation stage with water injection at a constant rate $Q_{i n j}$ for 2 hours (Fig. 1). It is assumed that the borehole is horizontal, in the plane of the analysed rock domain, and intersects the injection fracture in the shale-gas reservoir [11]. The injection occurs in all elements representing the initial $2 \mathrm{~m}$ long injection fracture. After 2 hours, water injection is stopped but simulation of hydro-mechanical behaviour continues for another hour.

\section{NUMERICAL APPROACH}

\subsection{Finite-difference numerical model}

A 2D finite-difference model was developed in FLAC3D ([13]) to study the coupled hydromechanical effects in scenarios SC1, SC2 and SC3 as a result of hydraulic fracturing stimulation. The model is a square region with $50 \mathrm{~m}$ side, with a thickness of $1 \mathrm{~m}$. A plane strain analysis was carried out. The mesh consists of 24100 elements and is more refined in a square region with $10 \mathrm{~m}$ side around the injection fracture where the elements are squares with $0.20 \mathrm{~m}$ side (Fig. 2). The bedding plane was considered to have a thickness of $0.20 \mathrm{~m}$. Three layers of elements were used to represent the bedding planes.

In our hydro-mechanical analysis, the injection fracture was assumed to have filling material to have capability to allow stress transfer through surface contacts. This is a more realistic scenario than simple open fracture because it enables the possibility of considering changes in the fracture aperture caused by changes in the effective stress normal to the fracture, as to be expected when two rough fracture surfaces are in contact. The injection fracture was modelled as an equivalent solid material, in which the elastic modulus $E_{F}$ of the elements intersected by a fracture trace is calculated according with the following equation ([15], [16]): 


$$
\frac{1}{E_{F}}=\frac{1}{E_{R}}+\frac{1}{k_{n} d}
$$

where $E_{R}$ is the elastic modulus of the intact rock, $k_{n}$ is the fracture normal stiffness, $d$ is the element size $(0.20 \mathrm{~m})$.

To check if the mesh resolution is sufficient to obtain a good estimate of the elastic stress distribution close to the injection fracture, scenario 1 was considered and a horizontal boundary stress $S_{h}$ of $40 \mathrm{MPa}$ was applied at the boundaries perpendicular to the $x$-axis. In this verification, the fracture was assumed to have no filling material or without stress transfer through surface contacts. The variation of the ratio between the magnitudes of the fracture normal stress $\sigma_{x x}$ and boundary stress $S_{h}$ with distance along the lines $x=0$ and $y=0$ away from the injection fracture was calculated and compared with the analytical solution presented in [17]. Results of this comparison showed that the difference between the solution provided by [17] and FLAC3D is smaller than $3 \%$, with exception of the stress at the very tip of the injection fracture, where this discrepancy is approximately $30 \%$. To obtain a better accuracy around the fracture tip, a more refined mesh would be necessary. Results obtained with a mesh with square elements of 0.10 and $0.05 \mathrm{~m}$ side showed that at the fracture tip the discrepancy between solution in [17] and FLAC3D is approximately $20 \%$ and $10 \%$, respectively. However, in our hydromechanical analysis, such refinement is not needed because the injection fracture is assumed to have filling material or to allow stress transfer through surface contacts and the local stress concentration at the fracture tip is much smaller. Results of our simulations done for scenario 1 showed that the discrepancy in fracture extension obtained by considering square elements with $0.05 \mathrm{~m}$ and $0.20 \mathrm{~m}$ side is about $0.50 \mathrm{~m}$, which is acceptable, considering the fracture propagates approximately $10 \mathrm{~m}$. This enables us to conclude that the stresses and fracture propagation due to water pumping are reasonably represented in our model.
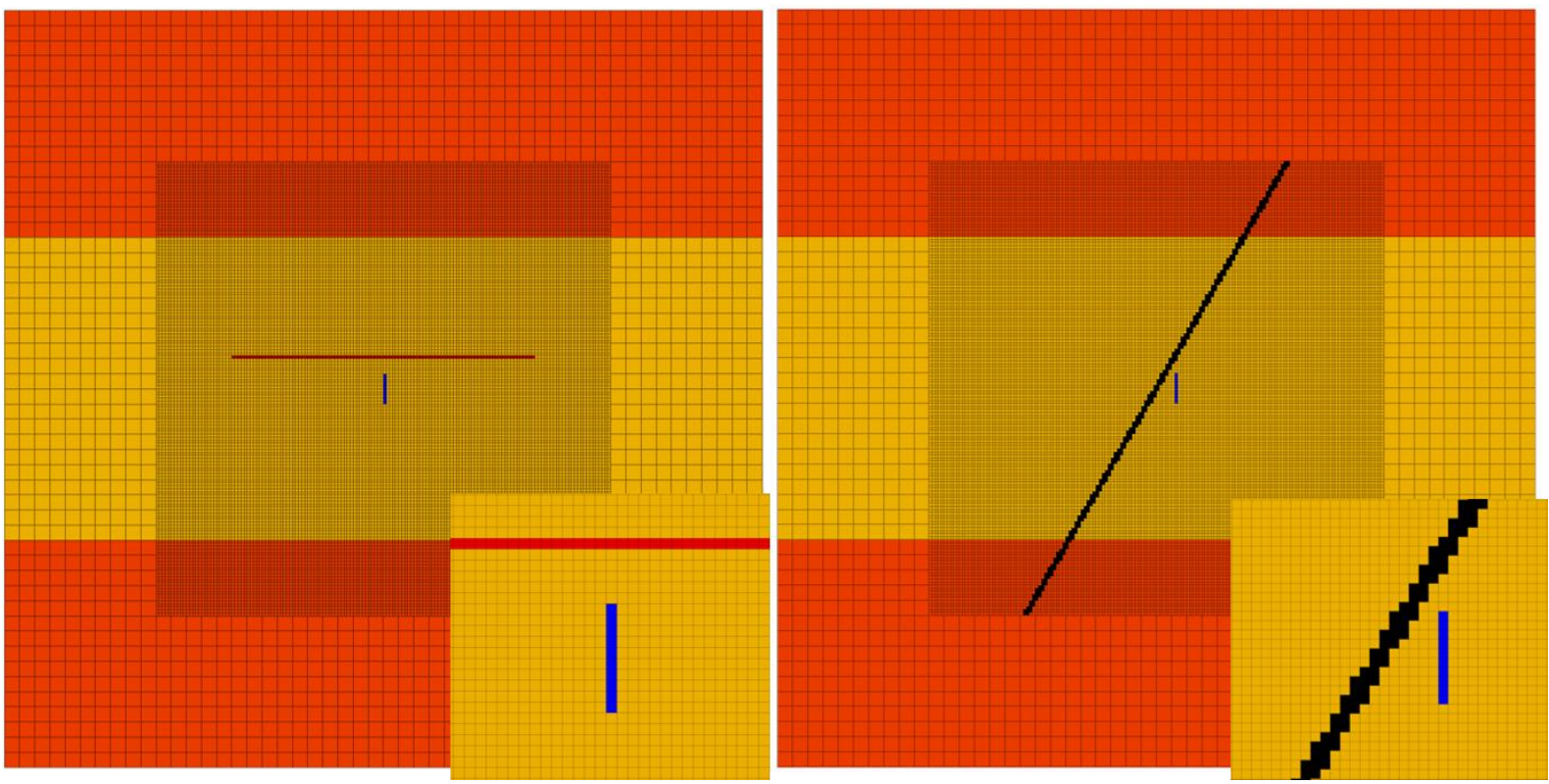

Fig. 2: Detail of the mesh of the finite-difference model used to simulate scenario 2 (left) and scenario 1643 (right) 


\subsection{Model parameters}

Necessary model parameters are listed in Table 1. A Mohr-Coulomb model with tension cut-off was used in the shale formation. An elastic modulus of $30 \mathrm{GPa}$ and Poisson's ratio of 0.2 were assigned in the base case of our study ([11]). The cohesion and friction angle were set to $30 \mathrm{MPa}$ and $25^{\circ}$, respectively. An elastic-brittle model was implemented in FLAC3D to describe the behaviour of the failure elements of the intact rock by tension and shear. This model is described in section 3.4. It was found that for these properties, shear failure does not occur in the shale formation and tension failure is the dominant mechanism. A tensile strength of $5 \mathrm{MPa}$ for the intact rock was assumed. By considering only the boundary stresses, a sensitivity analysis was done to study the influence of this parameter on the results. Additional values of 2 and $10 \mathrm{MPa}$ were considered. Results showed a slightly decreased fracture extension when the tensile strength increases. The fracture extension ranges between 10.4 and $11.2 \mathrm{~m}$ when the tensile strength ranges between 10 and $2 \mathrm{MPa}$, respectively. Regarding the hydraulic properties, the values of $10^{-19} \mathrm{~m}^{2}$ and 0.01 were assigned to the permeability and porosity of the shale formation ([11]).

The confining formations above and below the shale layer were assumed to have the same properties of the shale formation, with exception of the permeability, which was set to $10^{-16} \mathrm{~m}^{2}$. This is three orders of magnitude larger than the permeability of the shale formation. Further, a sensitivity analysis is made to study the influence of this parameter on the simulation results (see section 5.2).

The mechanical behaviour of the $2 \mathrm{~m}$ long injection fracture and its extension created by fracturing propagation is modelled with continuum elasto-plasticity using a Mohr-Coulomb constitutive model with tension cut-off. The mechanical properties of the injection fracture (Poisson's ratio, friction angle, dilation angle, cohesion) were extracted from [16]. The elastic modulus was calculated according to equation (1), by assuming a fracture normal stiffness of $1000 \mathrm{GPa} / \mathrm{m}$. A sensitivity analysis was done to study the influence of this parameter on the simulation results. Additional values of 100 and 500 $\mathrm{GPa} / \mathrm{m}$ were considered. Results showed very low sensitivity to this parameter and therefore do not affect the conclusions in this paper. The tensile strength for the injection fracture was assumed to be zero. Results of our simulations showed low sensitivity to this parameter, because the tension failure occurs in the intact rock. In the injection fracture, shear failure is the dominant mechanism for the scenario considered in our study. The permeability of the injection fracture was initially considered to be the same as that of the surrounding shale formation. The assumption of an initial impermeable fracture (hydraulically indistinguishable from the host rock) is a realistic base case, if the fracture is considered to be completely sealed initially ([18]). The porosity was assumed to equal to the porosity of the surrounding shale formation ([11]).

The mechanical behaviour of the fault and bedding plane was modelled by a Mohr-Coulomb model. The elastic properties of the bedding plane were assumed to be equal to those in the surrounding shale formation. Further, a sensitivity analysis is made to study the influence of the elastic modulus of the bedding plane on the simulation results (see section 5.3). However, the cohesion was set to $0 \mathrm{MPa}$ to enable the bedding plane to slide. The friction and dilation angles were set to $25^{\circ}$ and $10^{\circ}$, respectively. The properties of the fault were extracted from [11]. We set the Young's modulus and Poisson's ratio to $5 \mathrm{GPa}$ and 0.25 , respectively. This represents a significant reduction of the elastic modulus 
from the $30 \mathrm{GPa}$ value for the surrounding shale. The cohesion was set to $0 \mathrm{MPa}$. The friction and dilation angles were set to $31^{\circ}$ and $10^{\circ}$, respectively. We conducted also a sensitivity analysis by varying the permeability of the bedding plane and fault from $10^{-19} \mathrm{~m}^{2}$ (near impermeable base case) to $10^{-}$ ${ }^{16} \mathrm{~m}^{2}$, the latter case representing potential permeability along a thin damage zone (see sections 5.4 and 5.5).

Table 1: Rock characteristics considered in the base-case simulation

\begin{tabular}{|c|c|c|c|c|c|}
\hline Parameters & Shale & $\begin{array}{c}\text { Confining } \\
\text { formation }\end{array}$ & $\begin{array}{c}\text { Injection } \\
\text { fracture }\end{array}$ & $\begin{array}{c}\text { Bedding } \\
\text { plane }\end{array}$ & Fault \\
\hline Young's modulus $E(\mathrm{GPa})$ & 30 & 30 & 26 & 30 & 5 \\
\hline Poisson's ratio $v$ & 0.2 & 0.2 & 0.2 & 0.2 & 0.25 \\
\hline Rock density $\rho_{s}\left(\mathrm{~kg} / \mathrm{m}^{3}\right)$ & 2700 & 2700 & 2700 & 2700 & 2700 \\
\hline Cohesion $c(\mathrm{MPa})$ & 30 & 30 & 0 & 0 & 0 \\
\hline Tensile strength $\sigma_{t}(\mathrm{MPa})$ & 5 & 5 & 0 & 0 & 0 \\
\hline Friction angle $\phi\left(^{\circ}\right)$ & 25 & 25 & 25 & 25 & 31 \\
\hline Dilation angle $\psi\left({ }^{\circ}\right)$ & - & - & 5 & 10 & 10 \\
\hline Porosity $\phi$ & 0.01 & 0.01 & 0.01 & 0.01 & 0.01 \\
\hline Initial permeability $k\left(\mathrm{~m}^{2}\right)$ & $10^{-19}$ & $10^{-16}$ & $10^{-19}$ & $10^{-19}$ & $10^{-19}$ \\
\hline
\end{tabular}

\subsection{Injection rate}

For our 2D analysis, we simulated the water injection during stimulation as representative as possible of conditions during hydraulic fracturing operations. Generally, shale-gas stimulation requires a large volume of injected water to attain hydraulic fracturing. The water volume may exceed 500,000 gallons at each stage of hydraulic fracturing along a horizontal borehole ([19]). Typically, each stage is characterised by a sub-stage sequence, during which water may be pumped at a rate of 3000 gallons per minute (about $200 \mathrm{~kg} / \mathrm{s}$ ) for a few hours. From the total amount of water injected in a typical stage we estimated the injection rate into our 2D model as follows. A borehole is often 1000-2000 m long, and the hydraulic fracturing process may involve 10-20 stages. We thus assumed that each stage affected a length of about $100 \mathrm{~m}$ along the horizontal wellbore. Micro-seismic events observed at shale-gas production sites appear to indicate that the producing zone extends about $100 \mathrm{~m}$ along the vertical direction, and the lateral extent is about $300 \mathrm{~m}$. Thus, using these parameter estimates, we assumed an injection rate per volume unit during a single stage of $200 /(100 \times 100 \times 300)=6.6 \times 10^{-5}$ $\mathrm{kg} / \mathrm{s} / \mathrm{m}^{3}$, which correspond to an injection rate of $2 \times 10^{-6} \mathrm{~kg} / \mathrm{s}$ into a $0.04 \mathrm{~m}^{3}$ grid block. This injection rate was found to lead to a maximum pore pressure in the centre of the injection fracture of approximately 2.5 times the initial fluid pore pressure, at 30 minutes after water injection is started.

\subsection{Elastic-brittle model in the failure regions}

The behaviour of the intact rock undergoing tension or shear failure may be simplified to be represented by an elastic-brittle, elastic-strain softening (a combination of brittle and ductile) or elasticductile (plastic) mechanisms. An elastic-plastic and strain softening model cannot effectively simulate 
the fractures propagation because large plastic zones appear around the fracture tips. An elastic-brittle stress-strain relation, based on degradation of the mechanical properties and consequent stress distribution for the failure elements by tension and shear (Fig. 3) has been shown to be more effective for this purpose ([14], [20]). In this model, failure of an element causes disturbance of the local stress
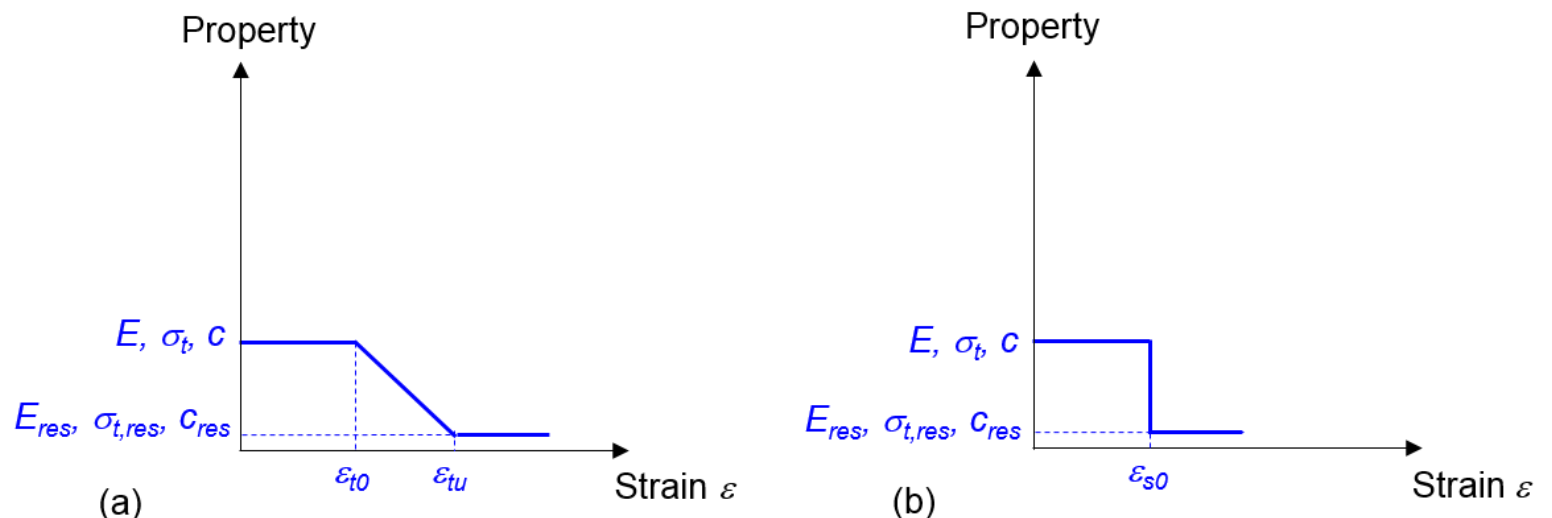

Fig. 3: Degradation of the stiffness and strength properties for the failure elements of the intact rock by (a) tension and (b) shear: $E, \sigma_{t}$ and $c$ are the initial values for elastic modulus, tensile strength and cohesion, respectively; $E_{\text {res }}, \sigma_{t, \text { res }}$ and $c_{\text {res }}$ are their residual values, respectively, $\varepsilon_{t 0}$ is the strain threshold of tension damage, $\varepsilon_{t u}$ is the limit strain of tensile strength and $\varepsilon_{s 0}$ is the strain threshold of shear damage.

According to this model, for the elements that undergo yield tensile strength (Fig. 3a), stiffness and strength properties are degraded, according to a damage variable $D$. This variable can be expressed by the following equations ([14]):

$$
\begin{gathered}
D=\left\{\begin{array}{l}
0, \varepsilon<\varepsilon_{t 0} \\
1-\frac{\sigma_{t, r e s}}{E \cdot \varepsilon}, \varepsilon_{t 0} \leq \varepsilon \leq \varepsilon_{t u} \\
1, \varepsilon>\varepsilon_{t u}
\end{array}\right\}, \\
\sigma_{t, r e s}=\eta \sigma_{t}, \\
\varepsilon=\sqrt{\left(\varepsilon_{1}\right)^{2}+\left(\varepsilon_{2}\right)^{2}+\left(\varepsilon_{3}\right)^{2}}
\end{gathered}
$$


where $\sigma_{t, r e s}$ is the residual tensile strength, $E$ and $\sigma_{t}$ are the elastic modulus and tensile strength of the intact rock (Table 1), $\eta$ is the residual strength coefficient, $\varepsilon_{t 0}$ is the strain threshold of tension damage, $\varepsilon_{t u}$ is the limit strain of tensile strength, and $\varepsilon_{1}, \varepsilon_{2}$ and $\varepsilon_{3}$ are the three principal strains.

For the elements subjected to shear failure (Fig. 3b), the damage variable $D$ can be expressed as follows ([14], [20]):

$$
D=\left\{\begin{array}{l}
0, \varepsilon_{s}<\varepsilon_{s 0} \\
1-\frac{\tau_{s, r e s}}{\varepsilon_{s} \cdot E}, \varepsilon_{s} \geq \varepsilon_{s 0}
\end{array}\right\}
$$

where $E$ is the elastic modulus, $\tau_{s, \text { res }}$ is the residual strength of shear damage, $\varepsilon_{s 0}$ is the strain threshold of shear damage, and $\varepsilon_{s}$ is the shear strain.

This model was implemented in our finite difference scheme. In the regions of the intact rock where the tensile stress exceeds the tensile strength, tension failure occurs. In those regions, the stiffness and strength properties were degraded. Stiffness degradation is implemented by simply updating elastic modulus $E$ in the stress-strain calculations, and strength degradation is modelled by reducing the tensile strength $\sigma_{t}$ and the cohesion $c$ of the intact rock. The friction angle was kept invariant ([14]). The corrected values for the elastic modulus $E_{\text {corr }}$, tensile strength $\sigma_{t, c o r r}$ and cohesion $c_{c o r r}$ are given by the following equations:

$$
\begin{gathered}
E_{\text {corr }}=E-\left(E-E_{r e s}\right) \times D, \\
\sigma_{t, c o r r}=\sigma_{t}-\left(\sigma_{t}-\sigma_{t, r e s}\right) \times D, \\
c_{c o r r}=c-\left(c-c_{r e s}\right) \times D,
\end{gathered}
$$

where $E_{\text {res }}, \sigma_{t, \text { res }}$ and $c_{\text {res }}$ are the residual values of the elastic modulus, tensile strength and cohesion (Fig. 3), respectively. In our simulations, the initial values of the elastic modulus, tensile strength and cohesion (Table 1) were reduced to one percent of the original values ([14]).

Shear failure was found to be the predominant mechanism in the elements that represent the bedding plane and the fault. In those elements, reducing shear strength with damage is not relevant, because they have a null cohesion, and they get into failure for a very small shear strain. For this reason, it was assumed that the shear strength and its residual value are null. In this way, according to equation (5), the damage variable $D$ is one when the elements get into shear failure, and this implies that the corrected values for the elastic modulus and tensile strength calculated with equations (6) and (7) are equal to their residual values. Because the tensile strength is null (Table 1), only elastic modulus degradation is considered. For the bedding plane and fault, the elastic modulus was considered to be 
one percent of its initial value ([14]). For the injection fracture, the elastic modulus is given by equation (1) and no damage was considered.

To check if this model enables to simulate properly the fracture propagation in intact rock, a study was conducted where (1) differential boundary stresses were applied in a model of a $2 \mathrm{~m}$ long fracture with inclination of $45^{\circ}$ to the maximum principal stress direction (vertical), with no filling material or stress transfer through surface contacts, (2) the fracture propagation was calculated for various values of the ratio $S R$ between the magnitudes of the maximum and minimum boundary stresses (e.g. $S R$ equal to 4, 5 and 10); and (3) the results were then compared with those estimated by analytical solutions obtained for an infinite elastic medium ([21]). For a ratio of 10 between the maximum and the minimum boundary stresses, the fracture extension was found to follow a line in the direction of the maximum principal stress. The difference between the fracture extension provided by analytical solutions and our simulations is smaller than $10 \%$, which enables to conclude that the length of the fracture extension is adequately represented in our model. With the mesh presented in section 3.1, the formation of wing cracks, as observed in [21], is not visible. For that purpose, a mesh with square elements of $0.05 \mathrm{~m}$ side around the fracture tip would be necessary. However, in the work reported in this paper, this is not relevant because the maximum ratio between the maximum and minimum boundary stresses is $1.67\left(S_{H}=0.6 S_{v}\right)$. For this small stress ratio, wing cracks do not form, even if a more refined mesh is used.

\subsection{Permeability changes in the fractures and tension failure regions}

We consider permeability changes with tensile and shear rupture in the initial and propagated fracture, bedding plane, and fault, according to a conceptual model described by [11]. In this model, the tensile and shear rupture regions are subjected to an increase in permeability, which is superimposed on the initial permeability. Changes in equivalent fractured rock permeability are a function of plastic strain $\varepsilon_{n}$ normal to the fracture, bedding plane or fault:

$$
k=k_{0}+k_{f}=k_{0}+A\left(\varepsilon_{n}-\varepsilon_{n}^{t}\right)^{3}
$$

where $k_{0}$ is the initial permeability of the fracture, bedding plane or fault, $A$ is a constant, and $\varepsilon_{n}{ }^{t}$ is a threshold strain related to required crack opening displacement for onset of permeability changes. Here, we used $\varepsilon_{n}^{t}=1 \times 10^{-4}$ and $A=1 \times 10^{-9}$, meaning that the permeability would increase to about $10^{-14}$ $\mathrm{m}^{2}$ for a plastic strain normal to the injection fracture on the order of $2 \times 10^{-2}$. This is a very substantial permeability change from an initial fracture permeability of $10^{-19} \mathrm{~m}^{2}$, one that provides rapid pressure diffusion along the fractured elements with fracture propagation.

\subsection{Coupled hydro-mechanical calculation}

A mechanical analysis is carried out by considering the boundary stresses $S_{v}$ and $S_{h}$ and the initial pore pressure $p$ of $20 \mathrm{MPa}$. Then, a flow analysis is performed to calculate changes in the pore pressure field resulting from water injection into the initial fracture (Fig. 1) at a constant flow rate $Q_{\text {inj }}$ during a 2 hours period. After 2 hours of injection, water injection is stopped. The increase in fluid pore pres- 
331 sure in the initial and propagated fracture and the surrounding intact rock leads to a decrease in the effective stress. In the regions where the tensile stresses exceed the tensile strength $\sigma_{t}$, tension failure occurs. In the regions where the shear stress exceeds the shear strength govern by Mohr-Coulomb criterion, shear failure occurs. Then, a mechanical analysis is made to calculate stress induced changes in permeability, as described in section 3.5. The coupled hydro-mechanical analysis is sequential and stepped forward in time. At each time step of transient flow calculation, a quasi-static mechanical analysis is conducted to calculate stress-induced changes in permeability. The simulation is performed for a simulation period of 3 hours (shut in occurs after 2 hours of injection). A mechanical analysis is done after each 60 seconds.

\section{RESULTS}

$342 \quad 4.1$ Results for failure regions and pore pressure field

Fig. 4 shows the failure regions and the pore pressure field after 2 hours of injection, obtained in scenarios 1, 2 and 3, whereas Fig. 5 shows results after 3 hours (one hour after shut-in). The upper and lower limits of the shale reservoir are represented by two red lines. Fig. 6 shows the time evolution of the pore pressure at the centre of the injection fracture (point 1) and the intersection of the fault with the extended fracture (point 2). The instants of time for which the extended fracture intersects the preexisting bedding plane or the fault are represented by dashed lines. Fig. 7 shows the variation of pore pressure and slip displacement in the fault after 2 hours of injection, as a function of distance $d$ along the fault from the point 2. 


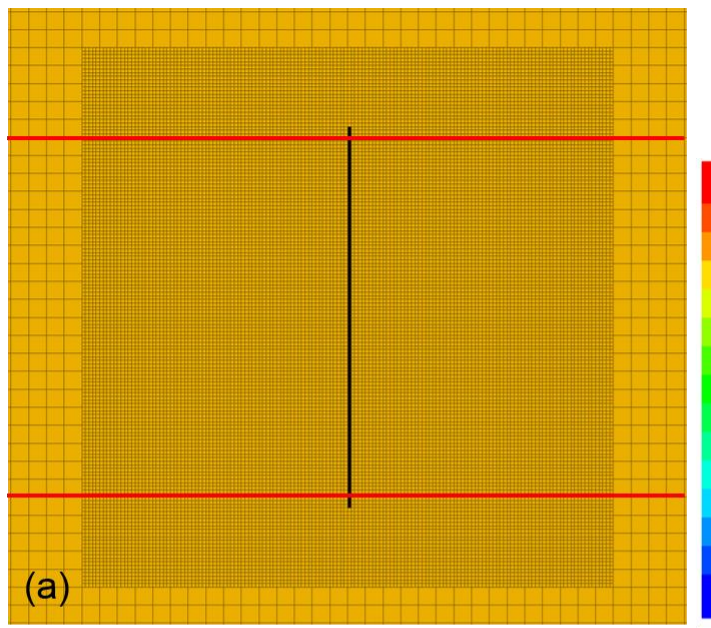

$3.5000 E+07$ $3.4000 \mathrm{E}+07$ $3.3000 \mathrm{E}+07$

$3.2000 \mathrm{E}+07$

$3.1000 \mathrm{E}+07$

$3.0000 \mathrm{E}+07$

$2.9000 \mathrm{E}+07$

$2.8000 \mathrm{E}+07$

$2.7000 \mathrm{E}+07$

$2.6000 \mathrm{E}+07$

$2.5000 \mathrm{E}+07$

$2.4000 \mathrm{E}+07$

2.3000E+07

2. $2000 \mathrm{E}+07$

$2.1000 \mathrm{E}+07$

$2.0000 \mathrm{E}+07$

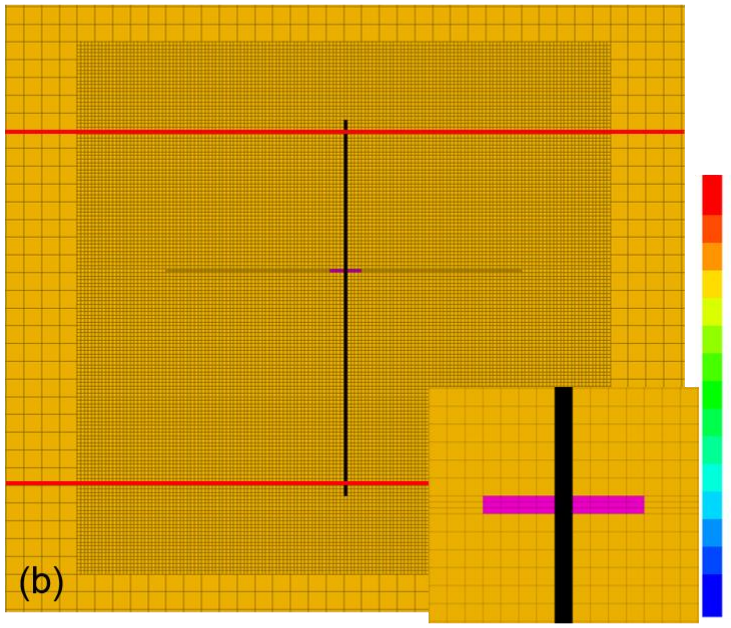

$3.5000 \mathrm{E}+07$ $3.4000 \mathrm{E}+07$ 3.3000E +07 $3.2000 E+07$ $3.1000 \mathrm{E}+07$ $3.0000 \mathrm{E}+07$ $2.9000 \mathrm{E}+07$ 2.8000E+07 $2.7000 \mathrm{E}+07$ $2.6000 \mathrm{E}+07$ $2.5000 \mathrm{E}+07$ $2.4000 \mathrm{E}+07$ 2.3000E+07 2.2000E+07 $2.1000 \mathrm{E}+07$ $2.0000 \mathrm{E}+07$

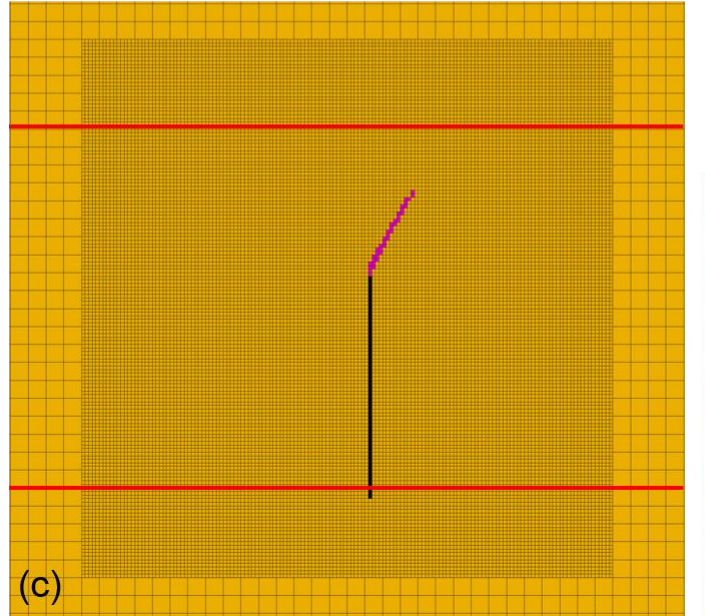

$3.5000 \mathrm{E}+07$ $3.4000 \mathrm{E}+07$ $3.3000 \mathrm{E}+07$

$3.2000 \mathrm{E}+07$

3. $1000 \mathrm{E}+07$

$3.0000 \mathrm{E}+07$

$2.9000 \mathrm{E}+07$

$2.8000 \mathrm{E}+07$

$2.7000 \mathrm{E}+07$

$2.6000 \mathrm{E}+07$

$2.5000 \mathrm{E}+07$

$2.4000 \mathrm{E}+07$

$2.3000 \mathrm{E}+07$

$2.2000 \mathrm{E}+07$

$2.1000 \mathrm{E}+07$ $2.0000 \mathrm{E}+07$

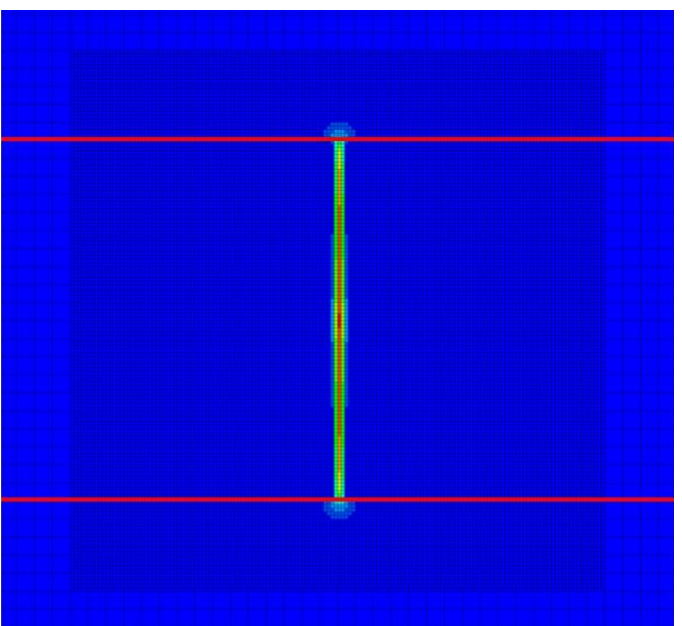

Fig. 4: Failure regions (left) and pore pressure field [Pa] (right) at the end of the 2 hours water injection 358 in (a) scenario 1 (b) scenario 2 and (c) scenario 3 (tension and shear failure regions are represented 359 by the black and pink colours, respectively)
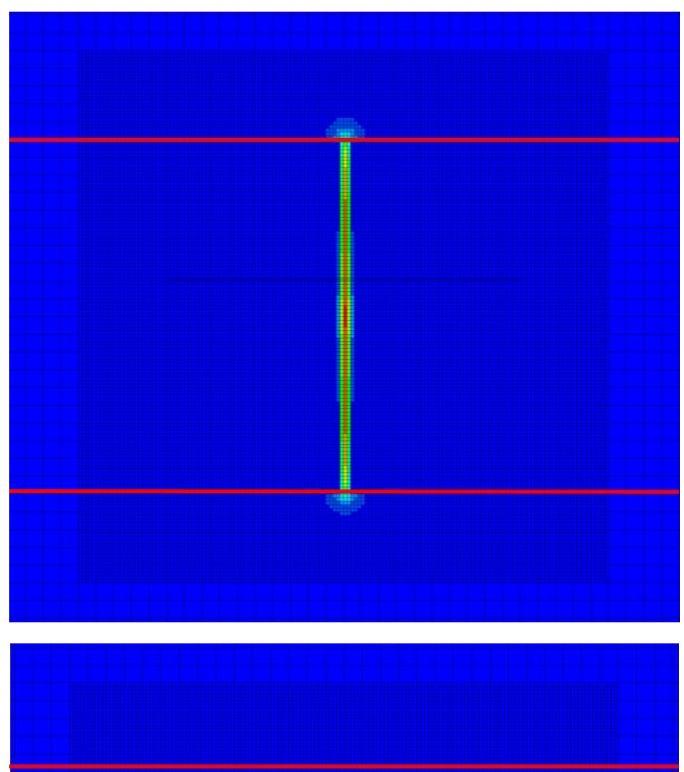


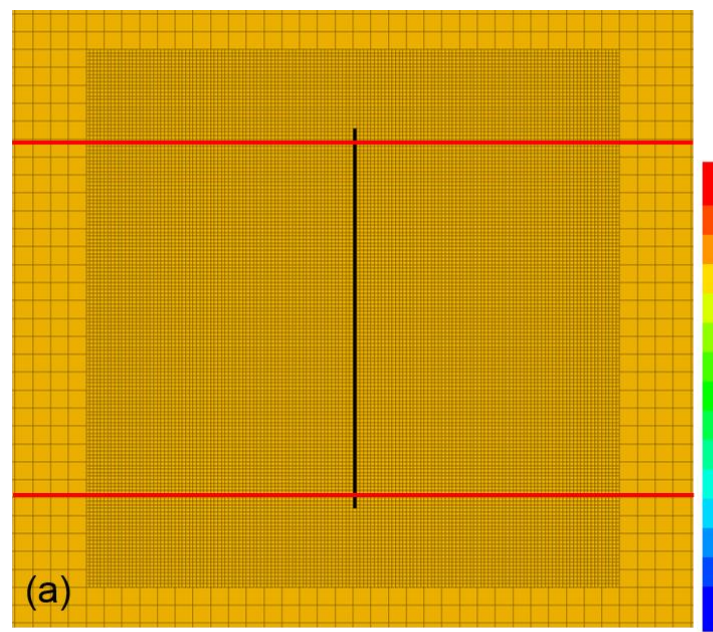

$3.5000 \mathrm{E}+07$
$3.4000 \mathrm{E}+07$ $3.3000 \mathrm{E}+07$

3.2000E+07 $3.1000 \mathrm{E}+07$ $3.0000 \mathrm{E}+07$

$2.9000 \mathrm{E}+07$

$2.8000 \mathrm{E}+07$

$2.7000 \mathrm{E}+07$

$2.6000 \mathrm{E}+07$

$2.5000 \mathrm{E}+07$

$2.4000 \mathrm{E}+07$

$2.3000 \mathrm{E}+07$

2.2000E+07

2.1000E+07 2.0000E+07

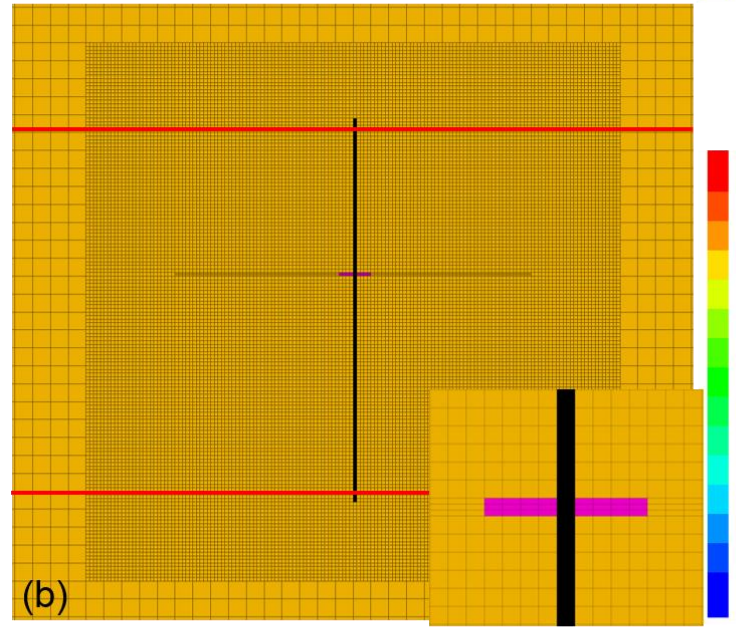

$3.5000 \mathrm{E}+07$ $3.4000 \mathrm{E}+07$

$3.3000 \mathrm{E}+07$ 3.2000E+07 $3.1000 \mathrm{E}+07$ $3.0000 \mathrm{E}+07$ $2.9000 \mathrm{E}+07$ $2.8000 \mathrm{E}+07$ $2.7000 \mathrm{E}+07$ $2.6000 \mathrm{E}+07$ $2.5000 \mathrm{E}+07$ $2.4000 \mathrm{E}+07$ $2.3000 E+07$ $2.2000 E+07$ $2.1000 \mathrm{E}+07$ $2.0000 \mathrm{E}+07$

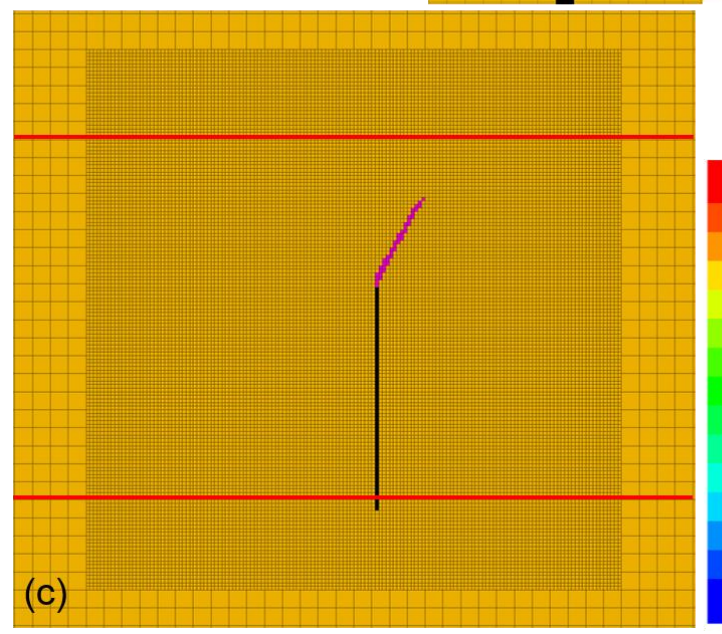

\section{$3.5000 E+07$ $3.4000 \mathrm{E}+07$ 3.3000E+07 \\ $3.2000 \mathrm{E}+07$ $3.1000 E+07$ $3.0000 E+07$ $2.9000 \mathrm{E}+07$ $2.8000 \mathrm{E}+07$ $2.7000 \mathrm{E}+07$ $2.6000 \mathrm{E}+07$ $2.5000 \mathrm{E}+07$ $2.4000 \mathrm{E}+07$ 2.3000E+07 $2.2000 \mathrm{E}+07$ \\ $2.1000 E+07$ $2.0000 \mathrm{E}+07$}
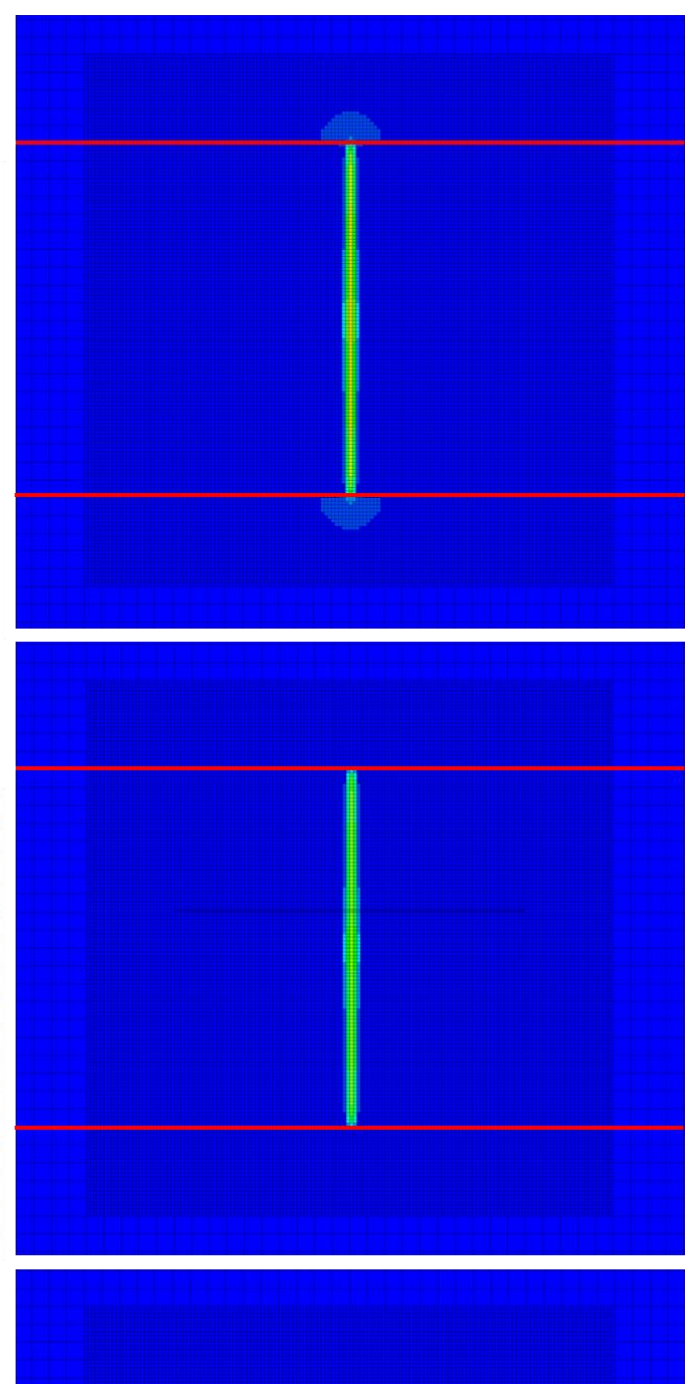

Fig. 5: Failure regions (left) and pore pressure field [Pa] (right) at 3 hours, after 2 hours of injection and one hour shut-in in (a) scenario 1 (b) scenario 2 and (c) scenario 3 (tension and shear failure regions are represented by the black and pink colours, respectively) 


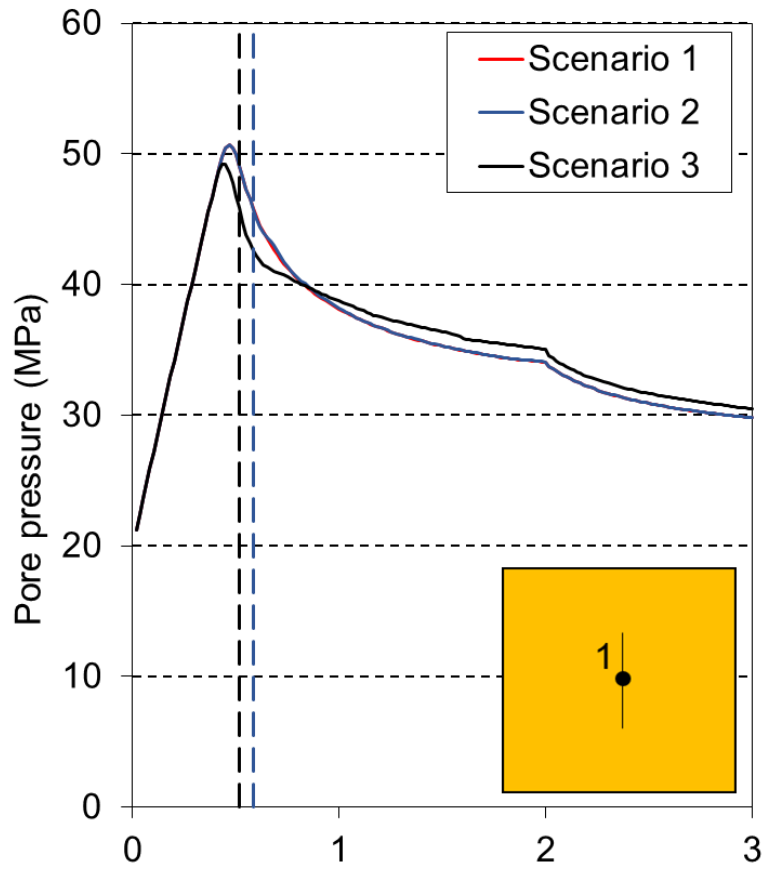

(a)

Time (hours)

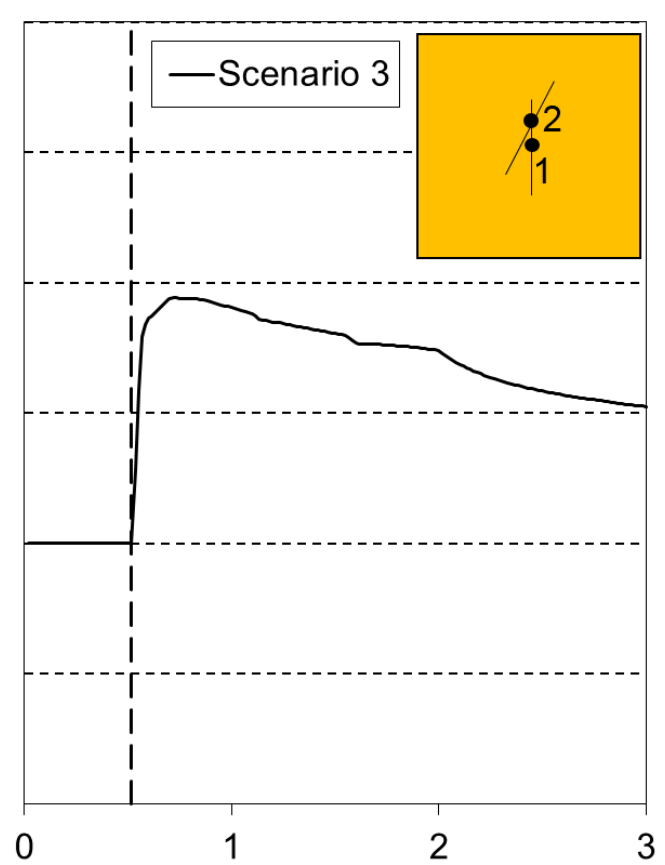

(b)

Time (hours)

374 Fig. 6: Time evolution of pore pressure in the (a) centre of the injection fracture (point 1) in all scenar375 ios and (b) the fault (point 2) in scenario 3
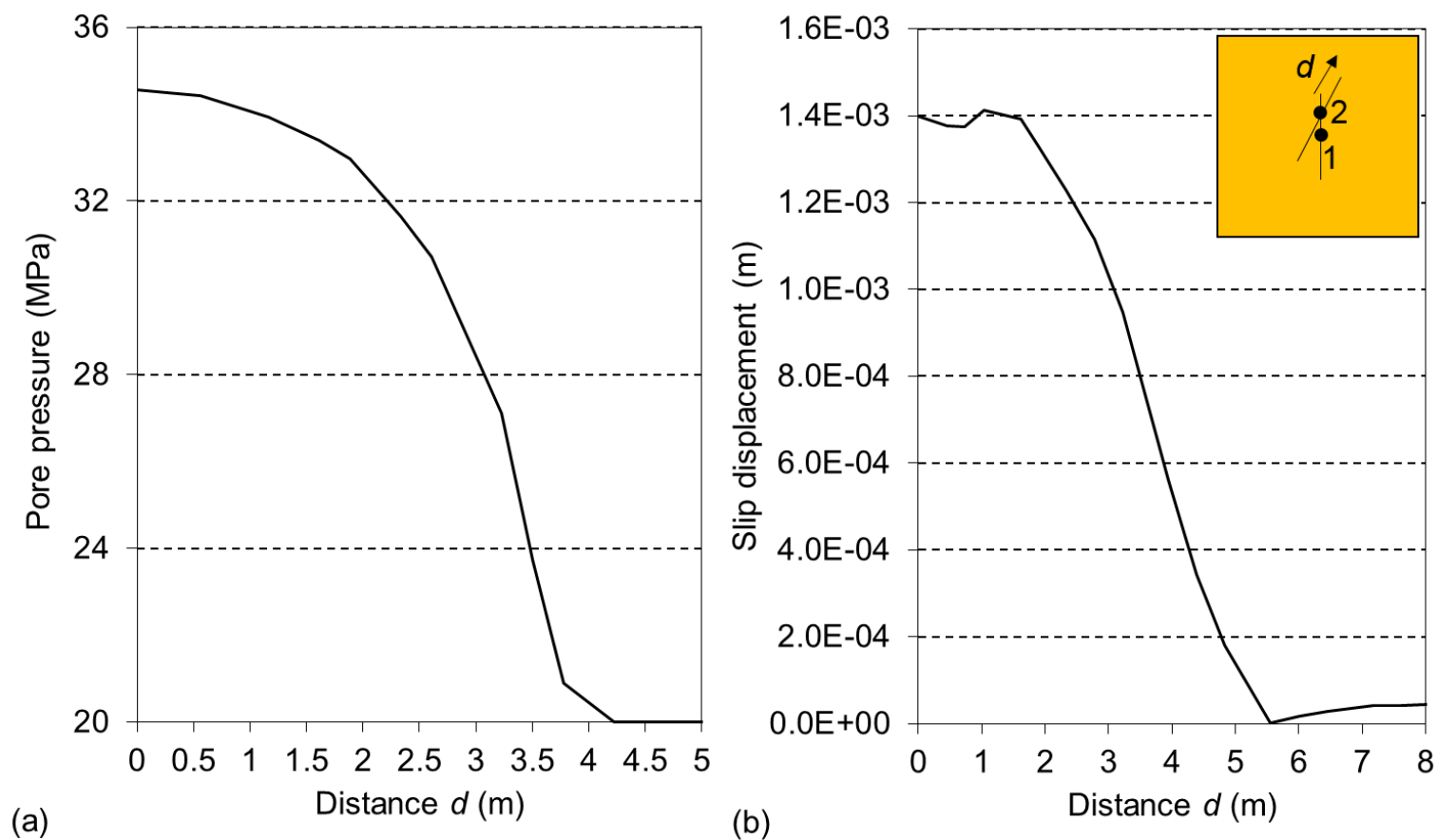

Fig. 7: Variation as a function of distance $d$ along the fault from the point 2 of (a) pore pressure and (b) slip displacement in the fault (results obtained after 2 hours of injection for scenario 3 )

In scenario 1, tension failure in the intact rock is the predominant mechanism (Figs 4 and 5). The injection fracture starts to propagate when the local pore pressure around the fracture tip is approxi383 mately $75 \%$ of the minimum boundary stress magnitude. The injection fracture propagates approximately $9.8 \mathrm{~m}$ in the maximum principal stress direction (vertical) and extents approximately $0.8 \mathrm{~m}$ up- 
wards into the confining formation. The pore pressure in point 1 increases until a maximum of 50.7 $\mathrm{MPa}$ is reached at approximately 30 minutes after the start of the water injection. After 30 minutes of injection, it was found that the pore pressure at the tip of the fracture is approximately $6 \mathrm{MPa}$ smaller than at its centre. This is because at this stage the fracture is too impermeable and thus the pore pressure diffusion through the fracture is a relatively slow process. Then, the fracture permeability starts to increase significantly (see section 4.2) and the injection pressure (point 1) decreases. The pore pressure diffusion is symmetrical to the $y$-axis and follows the fracture propagation. At approximately one hour after the start of the water injection the pore pressure along the fracture is practically uniform. At 2 hours of injection, the pore pressure in the centre of the injection fracture is approximately $34 \mathrm{MPa}$. At 1 hour after shut-in, the pore pressure in the injection fracture centre is approximately $30 \mathrm{MPa}$.

In scenario 2, the fracture propagation is found not to be influenced by the bedding plane because the fracture propagates in the maximum principal stress direction which is perpendicular to the bedding plane and the bedding plane is assumed to have the same elastic properties and initial permeability as those of the surrounding shale formation. In the bedding plane, shear failure is found to occur locally, and is caused by the opening the extended fracture. Along the bedding plane, there is no pore pressure diffusion, because permeability remains to be low. The variation of pore pressure with time is practically equal to that observed in scenario 1 .

In scenario 3, before the fracture reaches the fault, the pore pressure in the injection fracture increases approximately $1.6 \mathrm{MPa}$ less than in scenarios 1 and 2. This is because the fault, which is softer than the intact rock, leads to a slight increase in permeability of the injection fracture (see section 4.2) during that period. When the fracture reaches the fault, shear failure occurs in the fault element at the intercept, and the fracture does not propagate beyond it. At this point, the pore pressure in the fault (point 2) increases abruptly from $20 \mathrm{MPa}$ to approximately $37 \mathrm{MPa}$ (Fig. 6b). Because of changes in the fault permeability (see section 4.2), the fluid penetrates more along the fault which leads to shear failure and dilation in the adjacent elements. After 2 hours of injection, the length of the shear rupture zone in the fault is $5.1 \mathrm{~m}$ along the fault. Because of fault reactivation, the length of the propagating fracture is smaller than that in scenarios 1 and 2, which results in a smaller increase in injection fracture permeability (see section 4.2) and thus larger pore pressure. After 2 hours of injection, the injection pressure (point 1 ) is approximately $0.5 \mathrm{MPa}$ higher than that in scenarios 1 and 2 .

In all scenarios, before the end of the injection period, the fracture reaches the confining formations, and since those formations have a permeability three orders of magnitude larger than that of the shale formation, the pore pressure at the fracture tip decreases, and the fracture propagation is less. After shut-in, the pore pressure decreases even more and the fracture does not propagate any more (see Figs. 4 and 5).

Fig. 7 shows that after 2 hours of injection, the increase in the initial pore pressure $(20 \mathrm{MPa})$ is less than $1 \mathrm{MPa}$, from $d$ of approximately $3.7 \mathrm{~m}$ along the fault from the point of interception of the propagating fracture and the fault. The maximum slip displacement along the fault is approximately $1.4 \mathrm{~mm}$. For a $d$ larger than $5.5 \mathrm{~m}$, the slip displacement is smaller than $0.05 \mathrm{~mm}$, the element size. 


\subsection{Changes in permeability}

In this section, changes in permeability in the injection fracture and fault are analysed. Fig. 8 shows the time evolution of the permeability in the centre of the fracture (point 1) subjected to water injection and at the fault (point 2). The instants of time for which the extended fracture intersects the preexisting bedding plane or the fault are represented by dashed lines. Fig. 9 shows the distribution of the logarithm of permeability along the fault, after 2 hours of injection.

It can be seen in Fig. 8 that in all scenarios the permeability of the injection fracture starts to increase significantly approximately 30 minutes after the injection. This coincides with the instant in which the pore pressure starts to decrease (Fig. 6). The permeability increases for 2 hours injection period, and then decreases after shut-in. In scenarios 1 and 2, increases in permeability are similar, because the variation of the pore pressure with time in the injection fracture is similar (Fig. 6), which results in similar increases in permeability. In scenario 3 , because of fault reactivation, the length of the fracture extension is smaller than that in scenarios 1 and 2 , which results in less changes in injection fracture permeability. In scenario 3, when the fracture reaches the fault (point 2), at approximately 35 minutes, the fault permeability starts to increase. At 2 hours of injection, the fault permeability at point 2 is approximately five orders of magnitude larger than the initial value. At that instant, the permeability has increased by 3 and 2 orders of magnitude, at a distance $d$ of 3.5 and $4.5 \mathrm{~m}$ from point 2 , respectively (Fig. 9). For $d$ equal to $5 \mathrm{~m}$, changes in permeability are negligible, because there is no fault reactivation at that distance, as can be observed in Fig. 7. After shut-in, the permeability of the fault decreases as its aperture decreases.
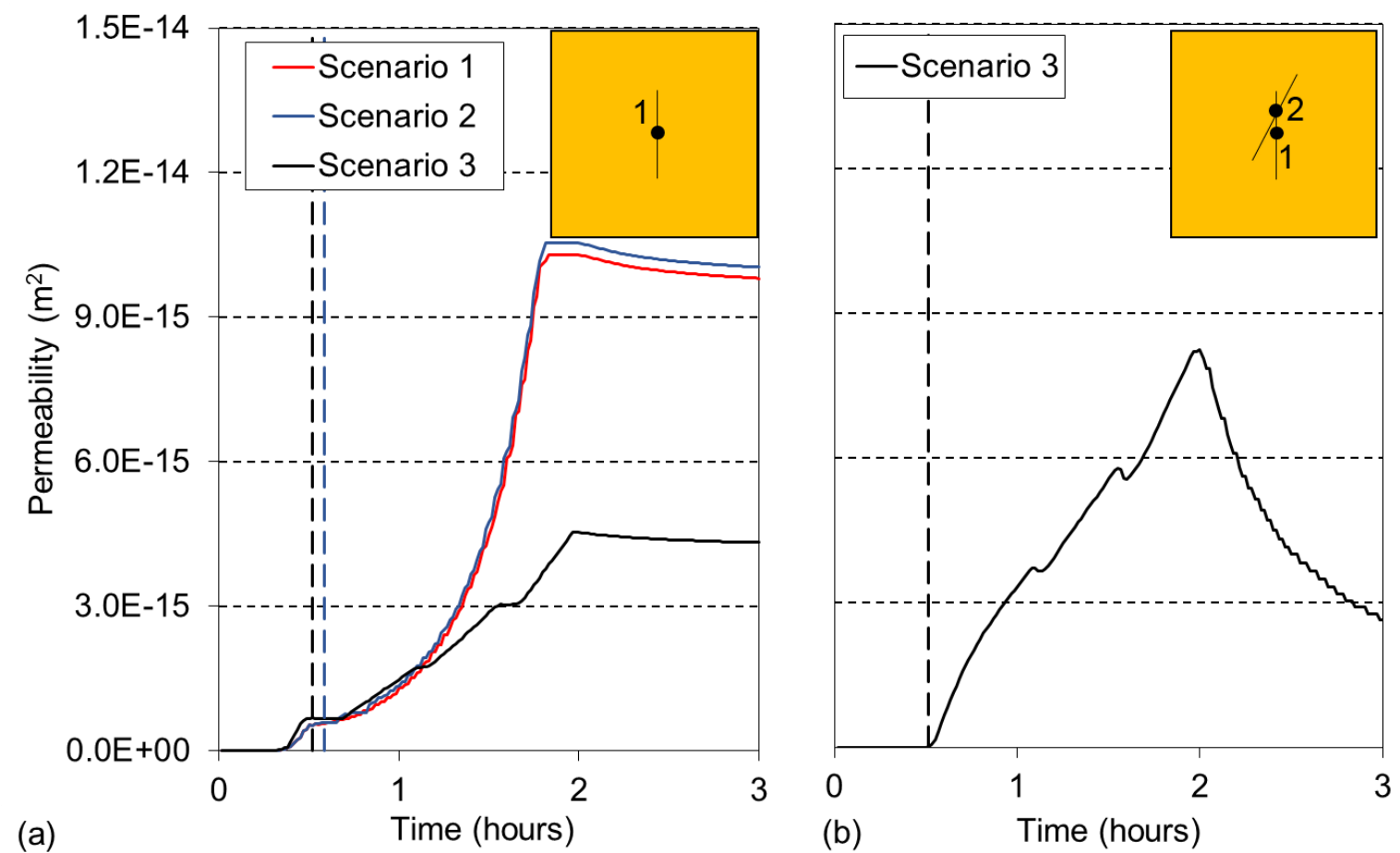

(b)

Time (hours)

Fig. 8: Time evolution of the permeability in the (a) centre of the injection fracture and (b) the fault 447 (point 2) 


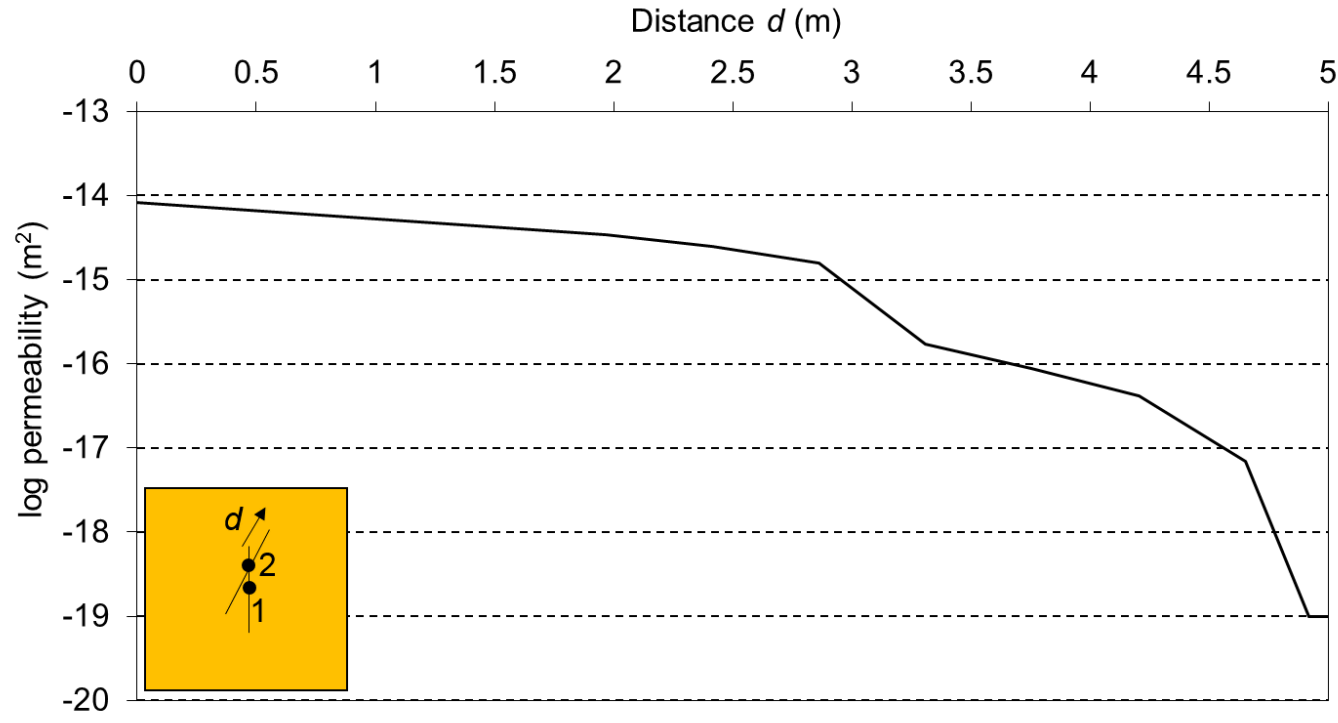

450 Fig. 9: Variation of the logarithm of permeability in the fault as a function of distance $d$ along the fault 451 to point 2 (results obtained after 2 hours of injection)

Table 2: Values of the key parameters considered in the sensitivity study

\begin{tabular}{|c|c|c|c|}
\hline \multirow{2}{*}{ Key parameter } & \multicolumn{2}{|c|}{ Parameter value } & \multirow{2}{*}{ Scenario } \\
\cline { 2 - 3 } & Base case & Sensitivity study & 1 \\
\hline $\begin{array}{c}\text { Stress ratio } S R \\
\text { meability } k_{c}\left(\mathrm{~m}^{2}\right)\end{array}$ & 0.7 & $0.6,0.8$ & 1 \\
\hline $\begin{array}{c}\text { Bedding plane elastic } \\
\text { modulus } E_{p}(\mathrm{GPa})\end{array}$ & 30 & 5 & 2 \\
\hline $\begin{array}{c}\text { Bedding plane initial per- } \\
\text { meability } k_{p}\left(\mathrm{~m}^{2}\right)\end{array}$ & $10^{-16}$ & $10^{-16}$ & 2 \\
\hline $\begin{array}{c}\text { Fault initial permeability } \\
k_{F}\left(\mathrm{~m}^{2}\right)\end{array}$ & $10^{-19}$ & $10^{-16}$ & 3 \\
\hline
\end{tabular}




\subsection{Effect of the ratio $S R$ between the magnitudes of horizontal and vertical stresses}

The fracture extension and the pore pressure field were calculated for a stress ratio $S R$ of 0.6 and 0.8. Results were compared with those presented in section 4 , obtained for $S R$ equal to 0.7 . Only scenario 1 was considered in this analysis. When $S R$ is equal to 0.6 , it was found that the extended fracture propagates further and reaches the horizontal boundaries of the model domain, so that a model with larger dimensions would be necessary to calculate the fracture extension. Fig. 10 shows the fracture extension and the pore pressure field obtained for a stress ratio $S R$ of 0.8 . The fracture propagation ranges between approximately 6 and $9.8 \mathrm{~m}$ when the stress ratio ranges between 0.8 and 0.7 , respectively. In contrast to the cases where $S R$ is set to 0.6 and 0.7 , the extended fracture for the $S R=0.8$ case does not reach the confining formations and as a result there is no pore pressure diffusion in those formations. After 2 hours of injection, the pore pressure is $41 \mathrm{MPa}$, instead of $34 \mathrm{MPa}$ for the $S R=0.7$ case.

Let us now assume that the stress ratio in the shale formation is 0.7 , but it is 0.8 or 1.0 in the confining formations. This scenario may result from Poisson's ratio values in the confining formations being larger than those in the shale formation, which leads to larger horizontal stresses in the confining formations. When $S R$ in the confining formations is equal to 0.8 , it was found that the extended fracture still reaches the confining formations, although its propagation is smaller than that observed when $S R$ is equal to 0.7 in the overall model. When $S R$ in the confining formations is equal to 1.0 , it was found the fracture propagation stops before it reaches the confining formations (Fig. 11). This shows that as the horizontal stresses in the confining formations increase, the fracture propagation is retarded.

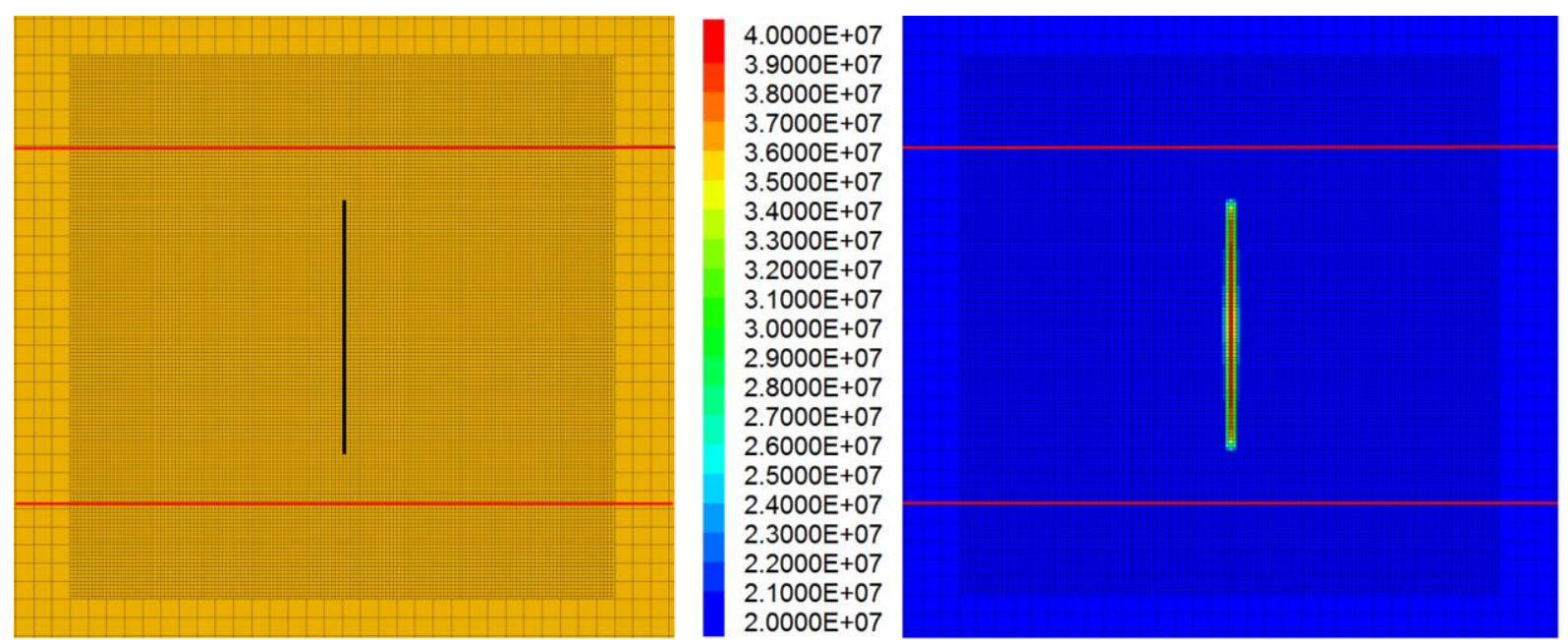

488 Fig. 10: Fracture extension (left) and pore pressure field [Pa] (right) obtained with a stress ratio $S R$ of 4890.8 (results obtained for scenario 1) 

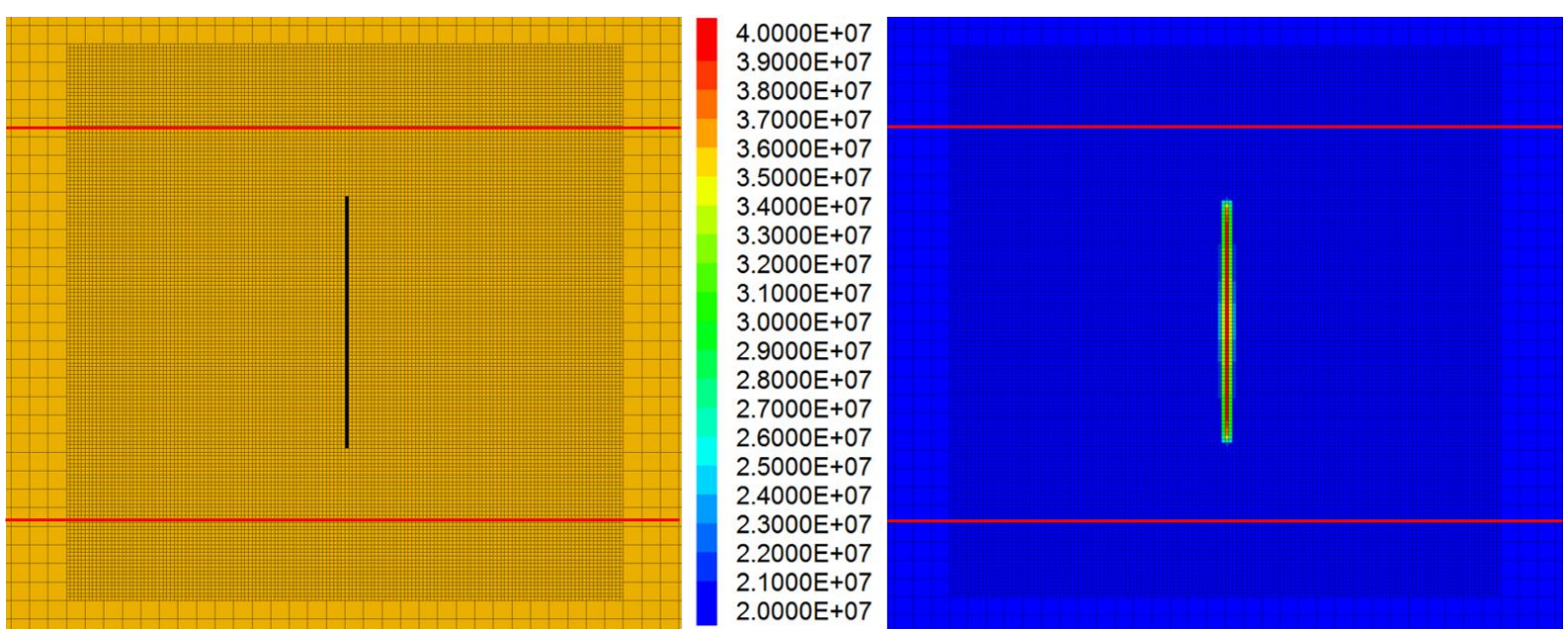

Fig. 11: Fracture extension (left) and pore pressure field [Pa] (right) obtained with a stress ratio $S R$ of 0.7 and 1.0 in the shale and confining formations, respectively (results obtained for scenario 1)

\subsection{Effect of the permeability $k_{c}$ of the confining formations}

The permeability $k_{c}$ of the confining formations was reset to $10^{-19} \mathrm{~m}^{2}$ and the fracture propagation was calculated. Only scenario 1 was considered in this analysis. It was found that in contrast to the results for $k_{c}$ of $10^{-16} \mathrm{~m}^{2}$, the fracture continues to propagate and reaches the horizontal boundaries of our model. This is because when the permeability of the confining formations is equal to the permeability of the shale formation, the injection pressure does not decrease when the fracture reaches the confining formations. Another simulation was done by considering $k_{c}$ equal to $10^{-19} \mathrm{~m}^{2}$, but considering in the confining formations having a stress ratio $S R$ of 1 instead of 0.7 . Results for fracture propagation and pore pressure field are presented in Fig. 12.

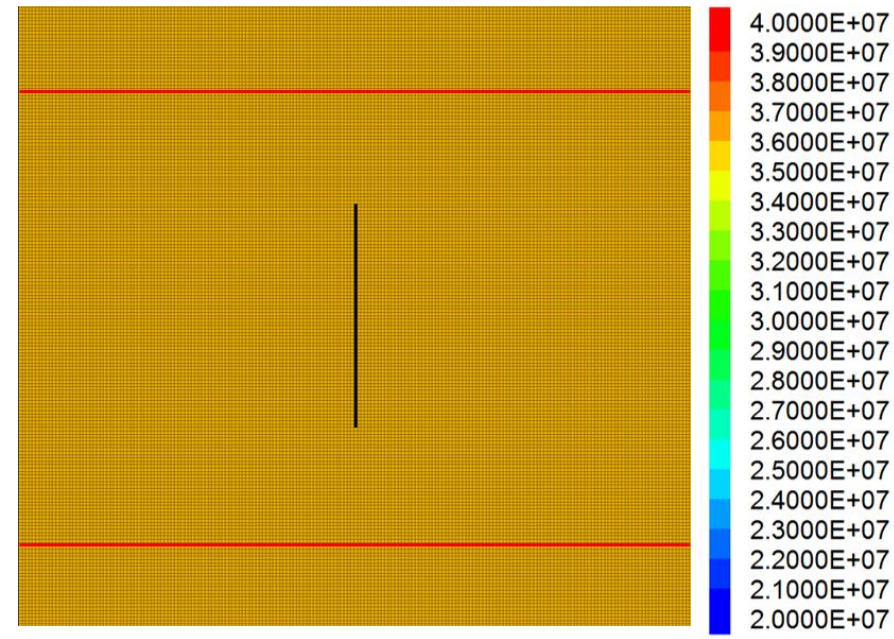

Fig. 12: Fracture propagation (left) and pore pressure field [Pa] (right) obtained with a permeability $k_{c}$ of the confining formations equal to $10^{-19} \mathrm{~m}^{2}$ and a stress ratio $S R$ of 1.0 in the confining formations (results obtained for scenario 1)

Results show that at the end of shut-in, the injection pressure is approximately $41 \mathrm{MPa}$, which is approximately $7 \mathrm{MPa}$ larger than that obtained for the case where $k_{c}$ equal to $10^{-16} \mathrm{~m}^{2}$ with a stress 
ratio $S R$ of 0.7 (see Fig $4 \mathrm{a}$ ). However, when $k_{c}$ is equal to $10^{-19} \mathrm{~m}^{2}$, the injection fracture propagates less and does not reach the confining formations because of the confinement provided by the horizontal stresses in those layers. In this case, a much higher fluid pore pressure would be required to continue to propagate the fracture.

\subsection{Effect of the elastic modulus $E_{p}$ of the bedding plane}

Fig. 13 shows the failure regions and pore pressure field, obtained for an elastic modulus $E_{p}$ of the bedding plane being set to $5 \mathrm{GPa}$. Results were compared with those presented in section 4 , where $E_{p}$ is equal to $30 \mathrm{GPa}$, same as that for shale formation. In this analysis, only scenario 2 was considered. Results show that for $E_{p}$ equal to $5 \mathrm{GPa}$, the propagation of the fracture upwards is $2.2 \mathrm{~m}$ less than that obtained with $E_{p}$ equal to $30 \mathrm{GPa}$, and hence the upper confining formation is not reached. The reason is that when the bedding plane is softer than the surrounding shale formation and as the propagating fracture reaches it, for a certain period of time, the increase in pore pressure at the fracture upper tip is less and is not enough to keep propagating the fracture upwards. During that time period, the fracture continues to propagate downwards. With time, the pore pressure starts to increase in the shale formation located above the bedding plane, and the fracture restarts to propagate upwards. The up-down asymmetry in fracture propagation with respect to the centre of the injection fracture is related with the period of time in which the fracture reaches the bedding plane and fracture propagation goes preferentially downwards.
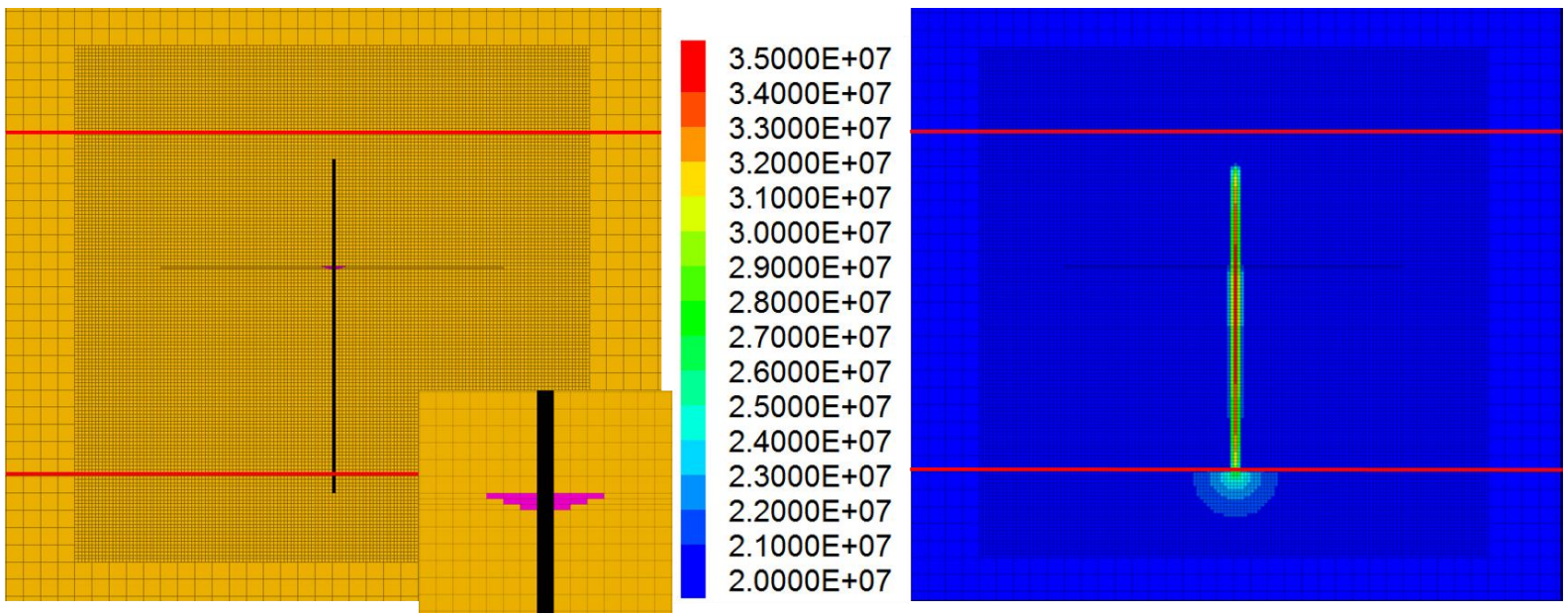

Fig. 13: Fracture propagation (left) and pore pressure field [Pa] (right) obtained with an elastic modulus of the bedding plane $E_{P}$ equal to $5 \mathrm{GPa}$ (results obtained for scenario 2 )

\subsection{Effect of the initial permeability $k_{p}$ of the bedding plane}

Fig. 14 shows the fracture propagation and pore pressure field, obtained for an initial permeability $k_{p}$ of the bedding plane of $10^{-16} \mathrm{~m}^{2}$. Only scenario 2 was considered in this analysis. Results were compared with those presented in section 4 , obtained for $k_{p}$ equal to $10^{-19} \mathrm{~m}^{2}$. Results show that when $k_{p}$ increases from $10^{-19} \mathrm{~m}^{2}$ to $10^{-16} \mathrm{~m}^{2}$, the propagation of the fracture upwards decreases significantly. The downward fracture propagation reaches the lower confining formation, as observed when $k_{p}$ is 
equal to $10^{-19} \mathrm{~m}^{2}$ but above the bedding plane it propagates only $2.4 \mathrm{~m}$ and does not reach the upper confining formation. For the more permeable bedding plane, pore pressure diffusion occurs in the bedding plane and the fracture propagation is interrupted for a certain period of time. During that period, the fracture continues to propagate downwards. Then, as the pore pressure diffuses into the shale formation above, the fracture restarts to propagate upwards again.

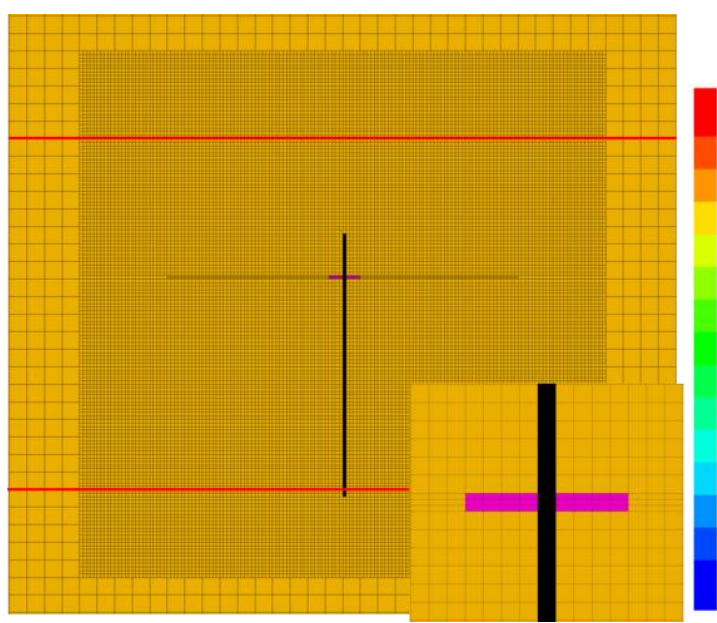

$3.5000 \mathrm{E}+07$

$3.4000 \mathrm{E}+07$

$3.3000 \mathrm{E}+07$

$3.2000 \mathrm{E}+07$

$3.1000 \mathrm{E}+07$

$3.0000 \mathrm{E}+07$

$2.9000 \mathrm{E}+07$

$2.8000 \mathrm{E}+07$

$2.7000 \mathrm{E}+07$

$2.6000 \mathrm{E}+07$

$2.5000 \mathrm{E}+07$

$2.4000 \mathrm{E}+07$

$2.3000 \mathrm{E}+07$

$2.2000 \mathrm{E}+07$

$2.1000 \mathrm{E}+07$

$2.0000 E+07$

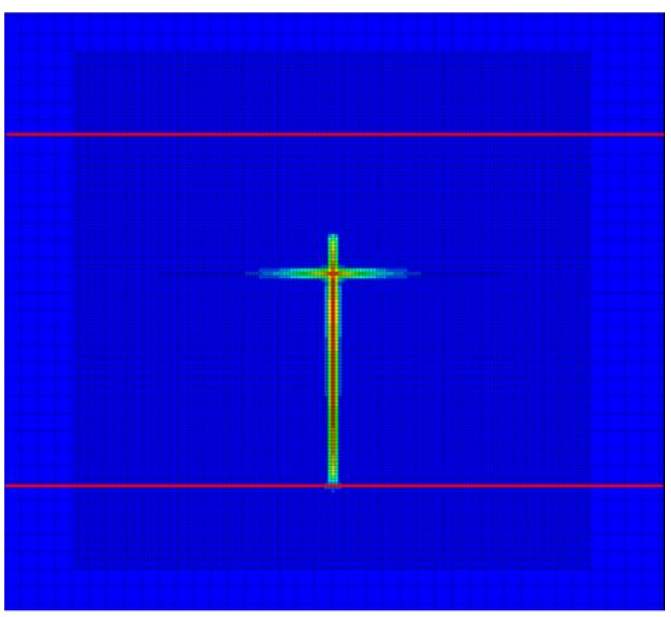

Fig. 14: Failure regions (left) and pore pressure field $[\mathrm{Pa}]$ (right) obtained with a permeability $k_{p}$ of the bedding plane equal to $10^{-16} \mathrm{~m}^{2}$ (results obtained for scenario 2): tension and shear failure regions are represented by the black and pink colours, respectively

\subsection{Effect of the initial fault permeability $k_{F}$}

Fig. 15 shows the failure regions and pore pressure field, obtained for an initial fault permeability $k_{F}$ equal to $10^{-16} \mathrm{~m}^{2}$. Results were compared with those presented in section 4 , obtained for $k_{F}$ equal to $10^{-19} \mathrm{~m}^{2}$. In this analysis, only scenario 3 was considered.
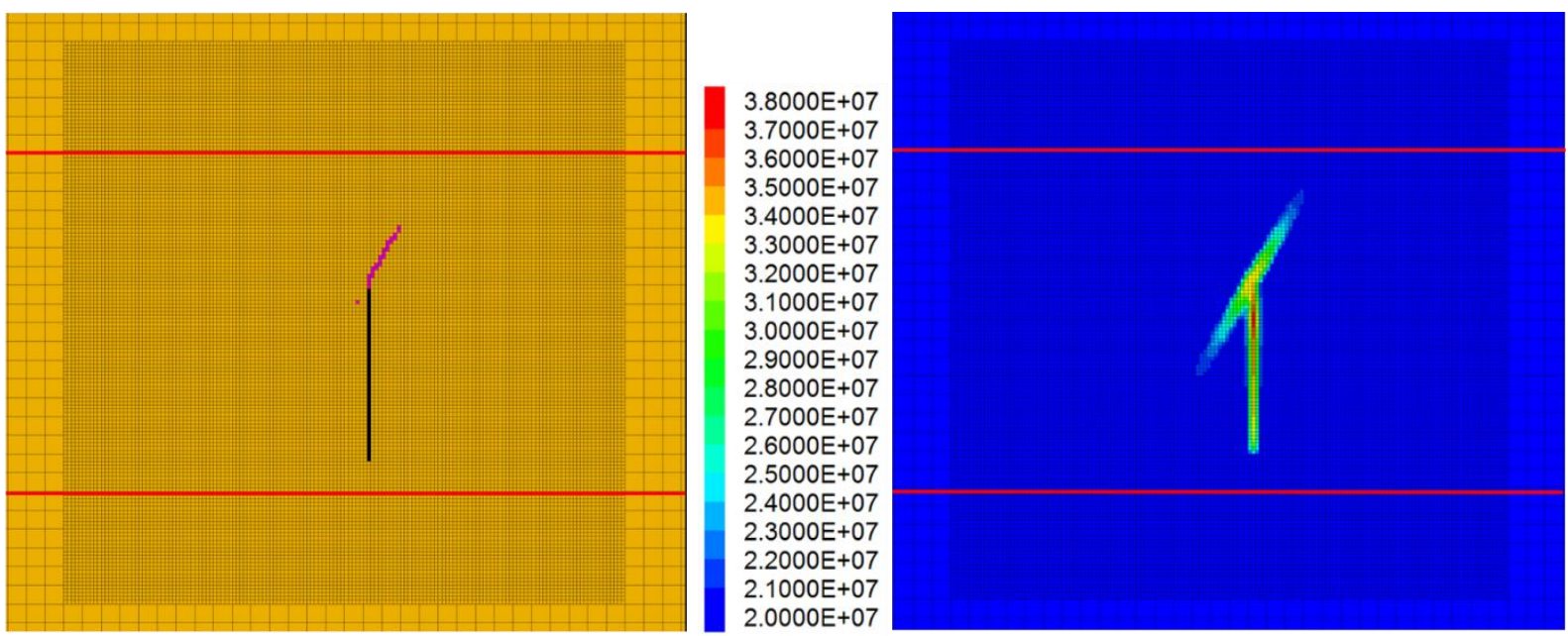

Fig. 15: Failure regions (left) and pore pressure field [Pa] (right) obtained with a fault initial permeability $k_{F}$ equal to $10^{-16} \mathrm{~m}^{2}$ (results obtained for scenario 3 ): tension and shear failure regions are represented by the black and pink colours, respectively 
Results show that when $k_{F}$ increases by three orders of magnitude, there is more fluid penetration and pore pressure diffusion into the fault. Thus, when $k_{F}$ is set to $10^{-16} \mathrm{~m}^{2}$, the pore pressure in the fault (point 2 in Fig. 6) is approximately $34 \mathrm{MPa}$ in contrast with $35 \mathrm{MPa}$ found when $k_{f}$ is equal to $10^{-19}$ $\mathrm{m}^{2}$. Because of this decrease in pore pressure, the length of the fault section where shear failure occurs decreases approximately $1.5 \mathrm{~m}$.

\subsection{Effect of the multiple bedding planes}

In this section, the influence of multiple bedding planes is analysed. Two additional cases were considered: (i) two bedding planes located $1 \mathrm{~m}$ and $2 \mathrm{~m}$ above the upper tip of the injection fracture, and (ii) three bedding planes located 1,2 and $3 \mathrm{~m}$ above the upper tip of the injection fracture. Results for fracture propagation are presented in Fig. 16. The analysis shows that the results are similar to those presented in section 4.1, obtained for a single bedding plane. This is because the bedding planes are perpendicular to the maximum principal stress direction and have the same initial permeability and elastic parameters of the surrounding shale formation. Shear failure only occurs locally, caused by the opening of the extended fracture, limited to the location of the bedding planes intercepted by the propagating fracture. If the bedding plane is softer than the shale formation, the propagation of the fracture will be retarded and becomes asymmetrical vertically with respect to the centre of the injection fracture, as shown in section 5.3.
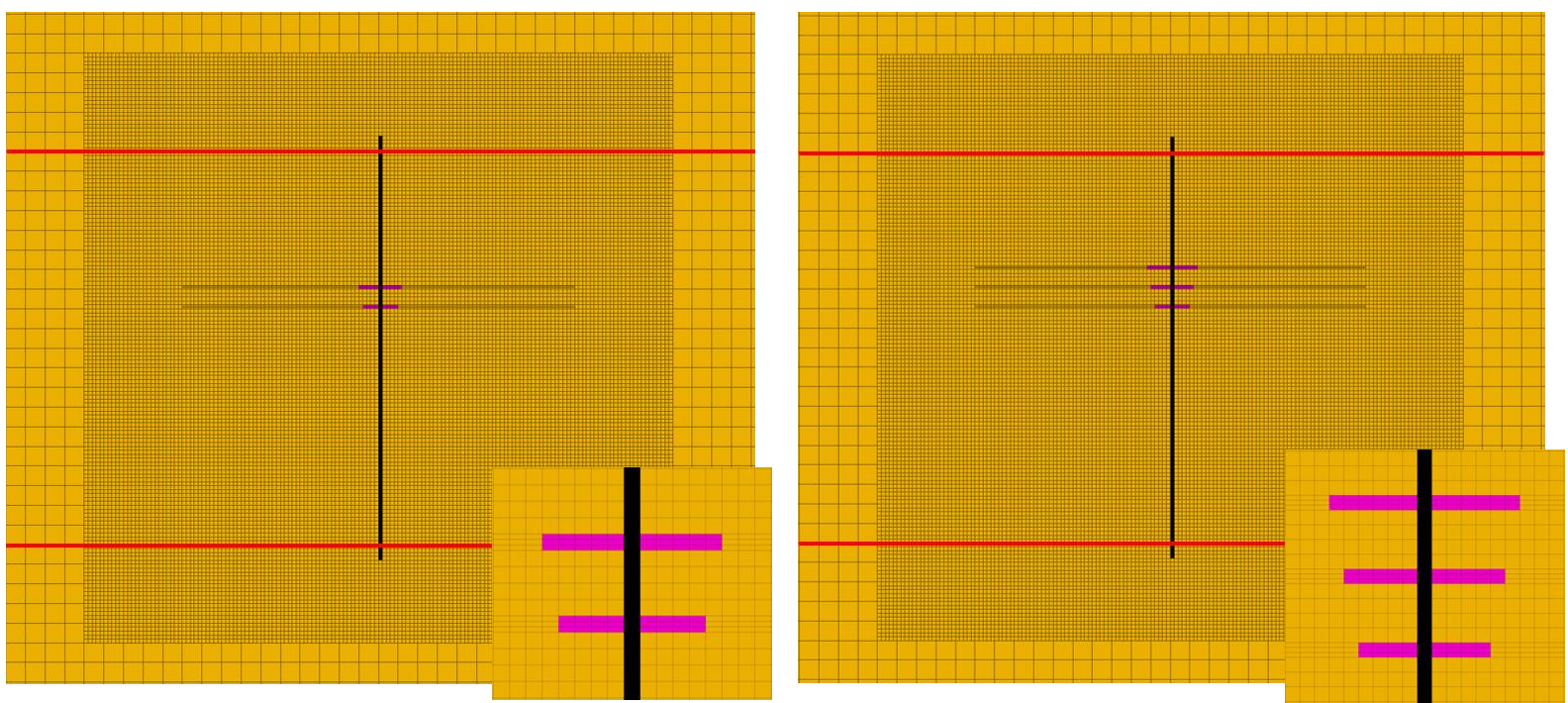

Fig. 16: Failure regions obtained with two bedding planes (left) and three bedding planes (right) located above the injection fracture (results obtained for scenario 2): tension and shear failure regions are represented by the black and pink colours, respectively

\section{CONCLUDING REMARKS}

The focus of the study is on understanding the influence of complex geological settings on hydraulic fracturing of shale-gas reservoirs. This is accomplished by a comparative coupled hydromechanical analysis of three scenarios of hydraulic fracturing starting from a $2 \mathrm{~m}$ long vertical injection 
591 fracture. In scenarios 1, 2 and 3, the respective influences of confining formations, pre-existing bedding plane and fault on the hydraulic fracturing process is studied. Simulations were made for a time period of 3 hours with an injection period of 2 hours followed by 1 hour of shut-in. A base case was considered in which the ratio $S R$ between the horizontal and vertical stresses is 0.7 , the permeability $k_{c}$ of the confining formations is $10^{-16} \mathrm{~m}^{2}$, the elastic modulus $E_{p}$ and permeability $k_{p}$ of the bedding plane are same as those of surrounding shale formation (30 GPa and $10^{-19} \mathrm{~m}^{2}$, respectively) and the initial fault permeability $k_{F}$ is $10^{-19} \mathrm{~m}^{2}$. A sensitivity study was made to analyse the influence of those key parameters on the simulation results. The effect of multiple bedding planes was also analysed. The general conclusions from the obtained results may be summarized as follows:

Firstly, the injection fracture starts to propagate when the local pore pressure around the fracture tip is approximately $75 \%$ of minimum boundary stress magnitude. This is when the tensile stress around the fracture tip is larger than the tensile strength of the intact rock. At that instant, the injection pressure is significantly larger than that at its tip because of the slow pore pressure diffusion along the fracture. After only one hour of water injection the pore pressure along the injection fracture is practically uniform. It was found that until the injection fracture starts to propagate, the injection pressure increases approximately linearly with time. This is because the shale formation is very impermeable and consequently the pore pressure diffusion into the intact rock is very slow.

Secondly, in cases where the propagated fracture reaches the confining formations with a significant larger permeability than that of the shale formation, the fracture propagation becomes slower. This is because the high permeability in the confining formations leads to a decrease in pore pressure at the extended fracture tip. After shut-in, pore pressure starts to dissipate and hence the fracture does not propagate any more.

Thirdly, the pre-existing bedding plane do not influence the simulation results when it is oriented perpendicular to the maximum principal stress direction and has the same initial permeability and elastic parameters as the shale formation. In such a scenario, multiple bedding planes have no influence on the results. When the bedding plane has softer properties than the surrounding shale, the results show a small up-down asymmetry in fracture propagation with respect to centre of the injection fracture, with a more limited upwards propagation.

Fourthly, shear failure and dilation were found to occur along the pre-existing fault inclined to the principal stress directions, which limited the fracture propagation upwards. Consequently, at the injection fracture, changes in permeability are less, which results in slightly higher pore pressure than that obtained without the pre-existing fault. At shut-in, the maximum discrepancy in pore pressure values obtained with and without the pre-existing fault was observed to be approximately $0.5 \mathrm{MPa}$.

Fifthly, it was found that fracture propagation is strongly influenced by the permeability $k_{c}$ of the confining formations, the ratio $S R$ between the horizontal and vertical stresses and the initial permeability $k_{p}$ of the bedding planes. Thus, the fracture propagation is more limited when (1) the confining formations are significantly more permeable than the shale formation, (2) the horizontal stresses in those confining formations are larger than in those in the shale formation or (3) the initial permeability of the bedding plane is larger than that of the surrounding shale. In the first and third cases, the pore pressure around the tip of the extended fracture decreases and the occurrence of tension failure in the 
intact rock is not so favourable, and in the second case, the horizontal stresses provide more confinement and the fracture requires more fluid pore pressure to propagate. On the other hand, when the initial permeability of the pre-existing fault is significantly larger than that of the shale formation, the pore pressure in the injection fracture increases less and the propagating fracture may not reach the confining formations.

\section{ACKNOWLEDGMENTS}

The authors gratefully acknowledge the Swedish Geological Survey (SGU), grant number 1724 , and the EU project Fracrisk grant number 640979, for providing financial support to research reported in this paper. Additional support was provided by the U.S. Department of Energy under contract No. DE-AC02-05CH11231.

\section{REFERENCES}

[1] Gu H, Siebrits E, Sabourov A. Hydraulic-fracture modelling with bedding plane interfacial slip. SPE Eastern Regional/AAPG Eastern Section Joint Meeting, 2008, Society of Petroleum Engineers, Pittsburgh, Pennsylvania, USA.

[2] Hanson ME, Shaffer RJ, Anderson GD. Effects of various parameters on hydraulic fracturing geometry. SPE 1980 Unconventional Gas Recovery Symposium, Pittsburgh.

[3] Lamont N, Jessen FW. The effects of existing fractures in rocks on the extension of hydraulic fractures. SPE $37^{\text {th }}$ Annual Fall Meeting, 1963.

[4] Zhang GM, Liu H, Zhang J, Wu HA, Wang XX. Three-dimensional finite element simulation and parametric study for horizontal well hydraulic fracture. J. Petrol. Sci. Eng. 2010; 72: 310-17.

[5] Teufel LW, Clark JA. Hydraulic fracture propagation in layered rock: experimental studies of fracture containment. SPE 1981 Low-permeability Gas Symposium. Denver, 1981

[6] Ribeiro P, Horne R. Pressure and temperature transient analysis: hydraulic fractured well application. SPE Annual Technical Conference and Exhibition, 2013, Society of Petroleum Engineers, New Orleans, Louisiana, USA.

[7] Adachi J, Siebrits E, Peirce A, Desroches J. Computer simulation of hydraulic fractures. Int. J. Rock Mech. Min. Sci. 2007; 44 (5): 739-57.

[8] Arthur JD, Bohm B, Layne M. Hydraulic fracturing considerations for natural gas wells of the Marcellus shale. In: Presented at the Ground Water Protection Council 2008. Annual Forum. Cincinati, Ohio, USA, 21-24, Sep.

[9] Zoback M, Kitasei S, Copithorne B. Addressing the Environmental Risks from Shale Gas Development Briefing Paper1. Natural Gas and Sustainable Energy Initiative, World watch Institute, Washington, July 2010.

[10] Hagström EL, Adams JM. Hydraulic fracturing: identifying and managing the risks. Environ. Claims J. 2012; 5 (2), 93-115 
[11] Rutqvist J, Rinaldi A, Cappa F, Moridis G. Modeling of fault reactivation and induced seismicity during hydraulic fracturing of shale-gas reservoirs. J. Petrol. Sci. Eng. 2013; 107: 31-44.

[12] Rutqvist J, Rinaldi A, Cappa F, Moridis G. Modeling of fault reactivation and seismicity by injection into a fault zone associated with hydraulic fracturing of shale-gas reservoirs. J. Petrol. Sci. Eng. 2015: 127: 377-86.

[13] Itasca. FLAC3D, Version 5.0. User's Manual. Itasca Consulting Group, Minneapolis; 2012.

[14] Li Y, Zhou H, Zhu W, Li S, Liu J. Numerical study of crack propagation in brittle joined rock mass influenced by fracture water pressure. Materials 2015; 8: 3364-76.

[15] Rutqvist J, Leung C, Hoch A, Wang Y, Wang Z. Linked multicontinuum and crack tensor approach for modeling of coupled geomechanics, fluid flow and transport in fractured rock. Journal of Rock Mechanics and Geotechnical Engineering. 2013; 5: 18-31.

[16] Figueiredo B, Tsang CF, Rutqvist J, Niemi A. A study of changes in deep fractured rock permeability due to coupled hydro-mechanical effects. Int. J. Rock Mech. Min. Sci. 2015; 79C: 70-85.

[17] Pollard DD, Segall P. Theoretical displacements and stresses near fractures in rock: with applications to faults, joints, veins, dikes, and solution surfaces. In: Fracture mechanics of rock, BK Atkinson, editor. Academic Press Inc; 1987. pp. 277-349.

[18] Croisé J, Schlickenrieder L, Marshall P, Boisson JY, Vogel P, Yamamoto S. Hydrogeological investigations in a low permeability clay stone formation: the Mont Terri Rock Laboratory. Phys. Chem. Earth 2004; 29: 3-15.

[19] US DOE, 2009. Modern Shale Gas Development in the United States: A Primer. U.S. Department of Energy Office of Fossil Energy and National Energy Technology Laboratory, April 2000.

[20] Fang Z, Harrison JP. Application of a local degradation model to the analysis of brittle fracture of laboratory scale rock specimens under triaxial conditions. Int. J. Rock Mech. Min. Sci. 2002; 39, 459-76.

[21] Mutlu O, Pollard D. On the patterns of wing crack along an outcrop scale flaw: a numerical modeling approach using complementarity. J. Geophy. Res. 2008; 113: B06403, doi: 10.1029/2007JB005284. 


\section{List of figures:}

Fig. 1: Geometry of the scenarios (a) SC1 (b) SC2 (c) SC3 and (d) boundary loading and pore pressure conditions: $S_{v}$ and $S_{h}$ are the vertical and horizontal boundary stresses, respectively; $S R$ is the ratio between $S_{h}$ and $S_{v} ; p$ is the initial fluid pore pressure; $Q_{i n j}$ is the constant flow rate Fig. 2: Detail of the mesh of the finite-difference model used to simulate scenario 2 (left) and scenario 3 (right)

Fig. 3: Degradation of the stiffness and strength properties for the failure elements of the intact rock by (a) tension and (b) shear: $E, \sigma_{t}$ and $c$ are the initial values for elastic modulus, tensile strength and cohesion, respectively; $E_{\text {res }}, \sigma_{t, r e s}$ and $c_{\text {res }}$ are their residual values, respectively, $\varepsilon_{t 0}$ is the strain threshold of tension damage, $\varepsilon_{t u}$ is the limit strain of tensile strength and $\varepsilon_{s 0}$ is the strain threshold of shear damage.

Fig. 4: Failure regions (left) and pore pressure field [Pa] (right) at the end of the 2 hours water injection in (a) scenario 1 (b) scenario 2 and (c) scenario 3 (tension and shear failure regions are represented by the black and pink colours, respectively)

Fig. 5: Failure regions (left) and pore pressure field [Pa] (right) at 3 hours, after 2 hours of injection and one hour shut-in in (a) scenario 1 (b) scenario 2 and (c) scenario 3 (tension and shear failure regions are represented by the black and pink colours, respectively)

Fig. 6: Time evolution of pore pressure in the (a) centre of the injection fracture (point 1) in all scenarios and (b) the fault (point 2) in scenario 3

Fig. 7: Variation as a function of distance $d$ along the fault from the point 2 of (a) pore pressure and (b) slip displacement in the fault (results obtained after 2 hours of injection for scenario 3 )

Fig. 8: Time evolution of the permeability in the (a) centre of the injection fracture and (b) the fault (point 2)

Fig. 9: Variation of the logarithm of permeability in the fault as a function of distance $d$ along the fault to point 2 (results obtained after 2 hours of injection)

Fig. 10: Fracture extension (left) and pore pressure field $[\mathrm{Pa}]$ (right) obtained with a stress ratio $S R$ of 0.8 (results obtained for scenario 1 )

Fig. 11: Fracture extension (left) and pore pressure field [Pa] (right) obtained with a stress ratio $S R$ of 0.7 and 1.0 in the shale and confining formations, respectively (results obtained for scenario 1)

Fig. 12: Fracture propagation (left) and pore pressure field [Pa] (right) obtained with a permeability $k_{c}$ of the confining formations equal to $10^{-19} \mathrm{~m}^{2}$ and a stress ratio $S R$ of 1.0 in the confining formations (results obtained for scenario 1 )

Fig. 13: Fracture propagation (left) and pore pressure field [Pa] (right) obtained with an elastic modulus of the bedding plane $E_{P}$ equal to $5 \mathrm{GPa}$ (results obtained for scenario 2)

730 Fig. 14: Failure regions (left) and pore pressure field [Pa] (right) obtained with a permeability $k_{p}$ of the 731 bedding plane equal to $10^{-16} \mathrm{~m}^{2}$ (results obtained for scenario 2): tension and shear failure regions are 732 represented by the black and pink colours, respectively

733 Fig. 15: Failure regions (left) and pore pressure field [Pa] (right) obtained with a fault initial permeabil734 ity $k_{F}$ equal to $10^{-16} \mathrm{~m}^{2}$ (results obtained for scenario 3 ): tension and shear failure regions are repre735 sented by the black and pink colours, respectively 
736 Fig. 16: Failure regions obtained with two bedding planes (left) and three bedding planes (right) lo-

1737

2

3738

4739

5

6740

741 Table 1: Rock characteristics considered in the base-case simulation are represented by the black and pink colours, respectively

\section{List of tables:} cated above the injection fracture (results obtained for scenario 2): tension and shear failure regions 